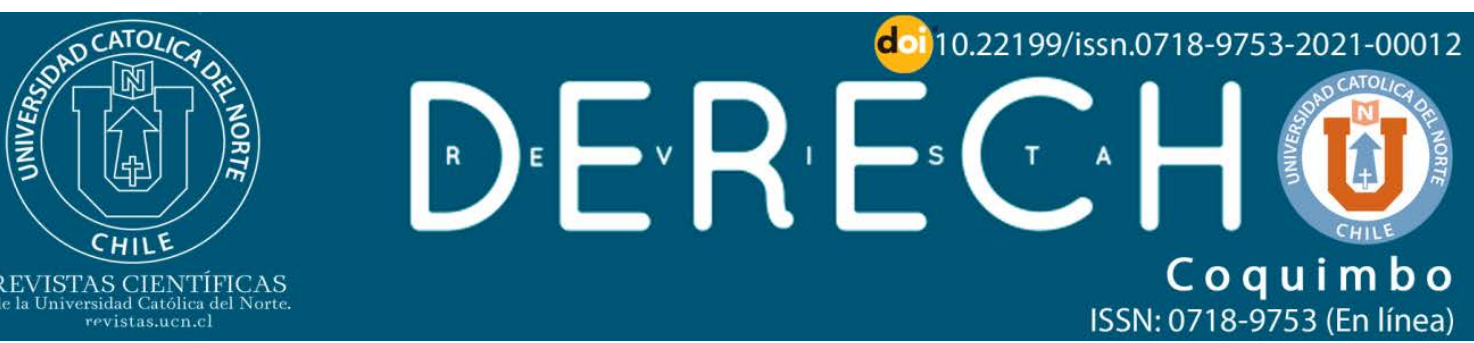

\title{
El tratamiento de las denominadas acciones neutrales a título de complicidad en el derecho penal alemán
}

\section{The treatment of the denominated neutral actions by title of com- plicity in german criminal law}

\author{
Miguel Antonio Schurmann Opazo' ${ }^{10}$ https://orcid.org/0000-0002-8454-3859 \\ 'Universidad de Chile, Santiago, Chile. Departamento de Ciencias Penales, Facultad de Dere- \\ cho. Profesor de derecho penal. Maestría en derecho, Universidad de Bonn.
}

mschurmann@derecho.uchile.cl.

(cc) BY

Resumen:

El objetivo es exponer críticamente las distintas aproximaciones que se han realizado sobre las denominadas acciones neutrales en la cultura jurídico-penal alemana, de modo a traer a la nuestra una discusión de parte general que, debido a la estructura de nuestra regulación penal vigente, es completamente pertinente. Por acciones neutrales se entienden generalmente comportamientos que aparentan ser inofensivos, pero cuya ejecución u omisión posibilita la realización de un delito, planteando la pregunta por las condiciones (objetivas o subjetivas) que deben verificarse para que a un sujeto le sea atribuido a título de complicidad el injusto cometido por otro. El problema dogmático planteado por este grupo de casos ha llamado la atención tanto de la doctrina como de la jurisprudencia, la que ha elaborado un criterio mixto (objetivo-subjetivo) que se ha constituido en la opinión dominante. El carácter dominante de una teoría muchas veces no coincide con su corrección, este es precisamente el caso. La respuesta correcta al problema se encuentra en la regulación legal de la complicidad y en los principios que rigen la participación.

Palabras Clave: Conductas neutrales; Comportamientos profesionales; Implicación; Accesoriedad; Participación.

\begin{abstract}
:
The aim is to critically present the different approaches that have been carried out on the socalled neutral actions in the German legalcriminal culture, so as to bring to ours a discussions of the general part that, due to the structure of our current penal regulation, is completely pertinent. Neutral actions are generally understood as behaviors that appear to be harmless, but whose execution or omission enables the realization of a crime, rising the question about the conditions (objective and/or subjective) that should be verified for a subject to be attributed by title of complicity the unjust committed by another. The dogmatic problem raised by this group of cases has called attention of both doctrine and jurisprudence, which have developed a mixed criterion (objective-subjective) that has become the dominant opinion. The dominant character of a theory often does not coincide with its correction. this is the case. The correct answer to the problem lies in the legal regulation of complicity and in the principles that govern participation.
\end{abstract}

Keywords: Neutral behaviors; Professional behaviors; Implication; Accessory; Participation.

\section{Fecha de recepción: 10 de julio de 2019 | Fecha de aceptación: 04 de marzo de 2020}


El tratamiento de las denominadas acciones neutrales a título de complicidad...

Even paranoids have real enemies -or so the saying goes. True or partially true conclusions are indeed often supported by bad reasons. Such is the case.

- Michael Moore, Causation and Responsibility, 2009.

\section{Introducción}

La posibilidad de que las acciones cotidianas, es decir, tanto acciones profesionales como aquellas denominadas neutrales, puedan ser calificadas como cooperación punible, es una de las preguntas más interesantes que ha requerido especial atención en Alemania en los últimos treinta años, no solo en la doctrina sino también en la jurisprudencia. Dicha pregunta ha sido abordada mediante un determinado grupo de casos, en los cuales la punibilidad de dichos comportamientos a título de complicidad ha sido especialmente discutida. Se trata de comportamientos que aparentan ser inofensivos ${ }^{1}$, pero cuya ejecución u omisión posibilita la realización de un delito, planteando la pregunta por las condiciones (objetivas y/o subjetivas) que deben verificarse para que a un sujeto le sea atribuido a título de complicidad el injusto cometido por otro. Aquel interés teórico, ha sido trasladado a nuestra cultura por distintas vías. Primero, a través de una extensa exposición del problema junto a una toma de postura por parte de Robles Planas (2003), en su obra dedicada a la participación delictiva y la delimitación normativa de esferas de responsabilidad, así como por las repercusiones que dicha exposición generó en la discusión de habla hispana. En cuanto a las repercusiones y a título meramente ejemplar: Rueda Martín (2015); Guzmán (2010); Tisnado Solís (2018). En segundo lugar, a través del tratamiento más bien tangencial que ha recibido el problema en nuestro país. El tratamiento del fenómeno ha sido realizado desde distintos puntos de vista. A propósito de los límites de la complicidad, ver: Viveros Vergara (2013). La relevancia para el ámbito del derecho penal económico es destacada por van Weezel de la Cruz (2007, p. 77 y ss.) a propósito de los delitos tributarios.

Dado que la constitución de la categoría ha sido desarrollada principalmente de la mano de grupos de casos -Roxin (1993b, Nm. 16) criticó el tratamiento previo no unitario de la categoría. El uso de casos es útil no solo para describir el problema, sino también para posibilitar la delimitación entre tipos de comportamientos lícitos e ilícitos, es por ello que comúnmente son usados casos para la argumentación. Una interesante elaboración de grupos de casos fue desarrollada por Wohlleben (1996, pp. 7 y ss., 32 y ss.) quien al comienzo de su monografía presenta distintos casos como objeto de su investigación y, posteriormente en el mismo texto, prueba las soluciones de los distintos autores sobre ellos. Es necesario precisar que la determinación del objeto de análisis mediante la agrupación de casos constituye una aproximación

\footnotetext{
${ }^{1}$ Este tipo de comportamiento abarca también a aquél que se encuentra en conformidad con determinados parámetros.
} 
metodológica diversa a aquella que, por ejemplo, propicia Roxin (2006b, pp. 230 y 231), al plantear la necesidad de abrir el sistema dogmático a "la naturaleza de las cosas" o a las circunstancias reales. Dicho sistema reconoce que los casos no entregan criterios de valoración jurídica que permita delimitar adecuadamente el objeto de análisis y su tratamiento, pero facilita la explicitación de los criterios y del tratamiento diverso que pueden presentar determinados subgrupos de ellos- para comprender mejor el objeto de referencia del problema es recomendable comenzar por la correcta y concentrada recopilación — desarrollada por Rengier- de casos susceptibles de ser abarcados por esta categoría:

Beispiele: Verkauf eines Brot- oder Taschenmessers oder Werkzeugs (Schraubenzieher, Hammer), das der Käufer zu einer Tötung, Verletzung oder einem Diebstahl benutzt; Verkauf von Streichhölzern an einen späteren Brandstifter; Verkauf eines Getränks, in das Gift gemischt werden soll, um jemanden zu töten; Verkauf von Kleidungsstücken zum Tarnen; Vermietung eines Fahrzeug an eine Diebesbande oder einen Täter, der damit, um Steuern zu hinterziehen, Gelder ins Ausland transportierten will; Fahrt von Täter zum Tatort durch Taxifahrer; Verlagerung von Kundengeldern ins Ausland durch Bankmitarbeiter, um Steuern zu hinterziehen ${ }^{2}$. (Rengier, 2016, p. 436) ${ }^{3}$

Con acento en los conocimientos de quien realiza la prestación, Roxin (1993b) presenta una constelación de casos similar y agrega uno interesante relativo al Derecho penal del medio ambiente: "Ist es Beihilfe zu Umweltstraftaten, wenn jemand Material an einen Fabrikanten liefert, von dem ihm bekannt ist, daß dieser bei der Verarbeitung ständig gegen Umweltschutzvorschriften verstößt?" (Nm. 16) ${ }^{4}$.

El planteamiento del problema en Alemania ha partido desde un diagnóstico mayoritario en la doctrina: no existe una restricción normativa suficiente en el propio $\S 27$ Strafgesetzbuch (StGB) ${ }^{5}$, para excluir la punibilidad de las conductas denominadas neutrales. Minoritariamente, todavía persisten en la literatura algunas opiniones que están a favor de renunciar a restricciones especiales (Niedermaier, 1995, p. 507). De acuerdo con dichas opiniones, es posible recurrir a los requisitos generales de responsabilidad penal para determinar la punibilidad de este especial grupo de casos, dado que no resulta aceptable para un sistema penal orientado por la protección

\footnotetext{
${ }^{2}$ Todas las traducciones, corresponden a versiones libres del alemán realizadas por el autor. (N. del E.)

3 "Ejemplos: la venta de un pan o un cuchillo de bolsillo o una herramienta (desatornillador o martillo) que es comprada por alguien que la utiliza para matar, lesionar o hurtar; la venta de fósforos a un productor de un incendio posterior; la venta de un bebestible en el cual será mezclado un veneno para matar a otro; la venta de prendas de vestir para camuflarse; el arriendo de un vehículo para una banda de atracadores o para alguien que quiere transportar dinero al extranjero para cometer evasión de impuestos; el traslado del autor desde el lugar del delito por un taxista; la transferencia de dineros de clientes al extranjero por parte de un funcionario de un banco para evadir impuestos".

${ }^{4}$ " ¿Es cómplice en un delito en contra del medio ambiente quien conscientemente entrega material a un fabricante que en su elaboración infringe permanentemente las prescripciones medioambientales?".

${ }^{5}$ Código Penal alemán.
} 
de bienes jurídicos un tratamiento privilegiado para estos -en este sentido Niedermaier (1995, p. 543); conforme, Beckemper (2001, p. 169)-. Ante ello, se plantean las siguientes preguntas: ¿debe otorgársele un tratamiento especial —-penalmente privilegiado- a estos comportamientos para limitar su punibilidad? En caso afirmativo, ¿en cuál nivel de la teoría general del delito? En el nivel del tipo objetivo, del tipo subjetivo, en una mezcla de ambos, o en el nivel de la antijuridicidad, son algunas de las propuestas. Pese a que el curso de la discusión alemana ha mostrado un progresivo acuerdo en los resultados de las propuestas -la convergencia de posiciones en su resultado es reconocida por van Weezel de la Cruz (2007, p. 83 y 84), quien la califica como una misma situación (las mismas características del hecho evaluado), observada desde perspectivas distintas-, este trabajo tiene como objetivo exponer críticamente las distintas aproximaciones que se han realizado sobre el tema en la cultura jurídico-penal alemana, de modo a traer a la nuestra una discusión de parte general que, debido a la estructura de nuestra regulación penal vigente, es completamente pertinente.

La discusión, se extiende no solo al tratamiento que deben recibir las denominadas acciones neutrales dentro de la dogmática de la participación, sino que también a su alcance. Bajo la misma denominación son identificados casos heterogéneos, en los cuales se apela a diversos principios para su tratamiento y solución. Algunas preguntas que habitualmente emergen - correcta o incorrectamente- en esta discusión son: ¿se encuentra permitido restringir la libertad de acción y de ejercicio profesional a través de la penalización de comportamientos cotidianos?, ¿qué función y efecto tienen en la imputación jurídico-penal la prohibición de regreso y el principio de confianza?, ¿pueden dichas acciones ser calificadas como la realización de un riesgo permitido o lícito?, ¿cuál es el fundamento penal de la complicidad y puede dicho injusto fundar suficientemente también la punibilidad de esta clase de acciones?, ¿qué rol juegan las reglas y expectativas del ámbito comercial para la imputación jurídico-penal?. Si bien el planteamiento de todas o parte de estas preguntas depende del punto de partida del autor que trate este problema, el principal libro en que todas ellas son reunidas y tratadas es Kudlich (2004). Con posterioridad a ella es necesario destacar Rackow (2007).

El único consenso alcanzado en este ámbito radica (paradójicamente) en que un consenso general - ya sea sobre un tratamiento unitario o diferenciado de este grupo de casos - no ha sido todavía alcanzado (Otto, 2001, p. 436). Una revisión de las últimas contribuciones arroja, que ellas han traído más complejidad que claridad al estado de la discusión (Wiegand, 1998, p. 198; en el mismo sentido, Joecks, 2017). Las distintas propuestas de tratamiento dependen de diversos principios $y$, naturalmente, las acciones neutrales pueden ser analizadas desde distintos puntos de vista. Por una parte, se encuentran quienes sostienen que este grupo de casos debería ser tratado analíticamente como uno propio de la parte general del Derecho penal, dado que la pregunta se relaciona con los límites del comportamiento punible (el primero 
en este sentido es paradigmáticamente, Jakobs, 1977, p. 1 y ss.). Por otra parte, se encuentran quienes sostienen que este problema tiene una posición conocida y determinada en la teoría de la participación, donde debe ser resuelto (opinan en ese sentido especialmente Kindhäuser, 2007a, y Wiegand, 1998, como lo prueba el título de su artículo). Adicionalmente, este tema tiene una notable importancia práctica en el ámbito del Derecho penal económico, por lo que muchos autores han tratado el problema de las acciones neutrales en relación con determinados tipos penales propios de dicho ámbito (Frisch, 2002, p. 539 y ss.), en el mismo sentido también Kindhäuser (2007a, p. 356). Un buen ejemplo sobre la utilidad de la discusión, lo constituye el artículo de Silva Sánchez (2008, p. 237 y ss.) sobre la punibilidad de los notarios en el marco de delitos de carácter económico, otro lo constituye el ejercicio de Momsen (2010, p. 561 y ss.) sobre el delito de uso de información privilegiada. Esta importancia práctica se ha mostrado también en numerosas decisiones del Bundesgerichtshof $(\mathrm{BGH})^{6}$, el cual ha desarrollado un criterio general para resolver este grupo de casos. El criterio vigente del BGH se construyó fundamentalmente entre los años 1998 y 2000, a través de las sentencias 5 StR 746/97 (1998) ("el caso del notario"); 5 StR 729/98 (1999) ("el caso del folleto comercial"); y 5 StR 624/99 (2000) ("el caso de la evasión de impuestos"), tal como se analizará en el apartado 1.3.2.

La pertinencia para el caso chileno de la discusión teórica llevada adelante en Alemania, se muestra desde ya por la similitud que exhiben las reglas que extienden la punibilidad -el carácter extensivo de la punibilidad no alude a que sea una ampliación del carácter típico de la conducta, sino que al carácter constitutivo de dicha regla (en oposición a meramente declarativo) en relación con la punibilidad del partícipe. En donde las reglas que regulan la complicidad punible no constituyen conductas típicas, sino que referidas al tipo, en los términos utilizados primigeniamente por Beling (citado en Contesse Singh, 2018, pp. 121 y ss.). Sobre el concepto de reglas constitutivas ver Searle (1997, p. 44 y ss.)- de los tipos de la parte especial en ambos sistemas jurídicos para el cómplice. De acuerdo al § 27.1 del StGB, traducido por López Díaz (1999) se sanciona como cómplice a "...quien haya prestado dolosamente ayuda a otro para la comisión de un hecho doloso antijurídico" (p. 10). Por su parte, nuestro Código Penal (1874) establece que "Son cómplices los que, no hallándose comprendidos en el artículo anterior [que regula a quienes se consideran como autores], cooperan a la ejecución del hecho por actos anteriores o simultáneos" (art. 16). De acuerdo con la fórmula defendida por la doctrina dominante en Alemania, la cooperación o prestación de ayuda del cómplice debe haber posibilitado, facilitado, intensificado o asegurado la realización del tipo (Kindhäuser, 2007a, p. 355). Entre nosotros, Garrido Montt (2017) prevé como requisito que el cómplice haya realizado "una actividad con anterioridad o en forma simultánea a la comisión del hecho, que objetivamente importe una colaboración del actuar del autor" (p. 419).

\footnotetext{
${ }^{6}$ Tribunal Supremo Federal Alemán.
} 
Es necesario tener presente que ya la misma denominación del problema es polémica (Schurmann Opazo, 2020, pp. 66 y ss.), dado que designar a acciones como "neutrales" y al mismo tiempo analizarlas como objeto de imputación penal constituye, en principio, una contradicción. Lo importante es reconocer que la denominación de las acciones como neutrales se corresponde con una aproximación fenomenológica y externa al Derecho penal que, en tanto reclama primacía como criterio para delimitar la punibilidad de un comportamiento a título de complicidad, debe ser supeditada al interés cognoscitivo propio del Derecho penal, que en este caso se encuentra gobernado por el esquema prototípico previsto para el cómplice. Sin perjuicio de la errónea denominación, la identificación de este grupo de casos se corresponde con un problema dogmático real que debe ser abordado por el derecho penal, pero bajo las categorías correctas (Schurmann Opazo, 2020, pp. 279 y 280). El objetivo de este trabajo, consiste en exponer sucintamente las diferentes propuestas que han elaborado tanto la doctrina como la jurisprudencia alemana para tratar el asunto — siguiendo las categorías utilizadas por sus autores para ello—, para concluir con una revisión crítica del estado de la discusión.

\section{El estado de la discusión. Propuestas teóricas de la doctrina y ju- risprudencia para delimitar la punibilidad de la complicidad a través de acciones neutrales}

Pese a que la Ley no reconoce a las denominadas acciones neutrales o cotidianas como una categoría, son numerosos los intentos de reconstrucción de criterios limitadores de formas de participación por medio de ellas. Las abundantes contribuciones sobre acciones "neutrales" en la dogmática penal alemana, muestran que existen diferentes posibilidades para presentar el estado actual de dicha discusión (una exposición actualizada y resumida del estado de la discusión aparece en Joecks, 2017, Nm. 66 y ss.; Kudlich, 2004, p. 74 y ss.; Kudlich, 2008, p. 226 y ss.; y Seher, 2009, 793 y ss.; y, Rackow, 2007, p. 51 y ss.). Una posibilidad es presentar una selección de autores (dicha alternativa elige Niedermaier, 1995, p. 508 y ss.). Otra alternativa es presentar una muestra de los criterios restrictivos, refiriéndose a los autores que con matices - adscriben sus teorías a dichos criterios (esta alternativa es elegida por Amelung, 1999, p. 10 y ss.; y, Otto, 2001, p. 436). Finalmente, se pueden distinguir las contribuciones en atención a la específica solución que le otorgan a los conocidos y comunes casos reales y teóricos a los que hacen referencia -casi todos toman posición en relación al denominado "caso de evasión de impuestos" (5 StR 624/99, 2000) ${ }^{7}$. Wohlleben (1996, p. 32 y ss.) presenta no solo propuestas, sino que también toma posición "in concreto" para cada caso-. En lo que se sigue se ha elegido la se-

\footnotetext{
${ }^{7}$ Una breve referencia se encuentra en 1.3.2.
} 
gunda alternativa, dado que ella contribuye en una mayor medida a la claridad analítica de la exposición ${ }^{8}$.

\subsection{Soluciones en el nivel de la tipicidad objetiva}

En este apartado, son expuestas críticamente las posturas que presentan una acentuada relevancia de los criterios objetivos de restricción de la punibilidad, sin perjuicio de las representaciones subjetivas del autor.

\subsubsection{La atipicidad de los comportamientos socialmente adecuados}

De acuerdo con la teoría general de la adecuación social, que tienes sus orígenes en Welzel (citado por Otto, 2001, p. 436), comportamientos adecuados socialmente son aquellos que se mantienen completamente dentro del marco de lo que históricamente se ha entendido como orden social de vida. Es por ello que no puede calificarse a una acción de dichas características como típica, pese a que podría tener como consecuencia la lesión de un bien jurídico. El punto de vista decisivo para dicha calificación, es cuan habitual y adecuado es un comportamiento a lo socialmente aceptado. Si dichos criterios son satisfechos, la conducta debe ser calificada como adecuada socialmente y, por ello, permitida. Acciones socialmente adecuadas son, por ejemplo, actividades como el transporte en tren, pese al riesgo de lesión que dicha actividad reporta para diversos bienes jurídicos (Welzel, 1975, p. 141). Así, y pese a la aparente tipicidad de una conducta, ella puede tener otra valoración, como conforme a Derecho, dado que no presenta un injusto material. Esta teoría, ha sido directa o indirectamente empleada por distintos autores modernos para excluir la punibilidad de las acciones neutrales.

El problema dogmático que presenta la apelación a conceptos como la adecuación social, puede ser generalizado. Una situación semejante, se presenta cuando se califica una acción como dentro del ámbito del riesgo permitido ${ }^{9}$ o se apela a una prohibición de regreso ${ }^{10}$ para excluir la punibilidad de una conducta previa a la principal. Se trata de conceptos indeterminados que son habitualmente utilizados para resolver problemas de calificación jurídica de conductas, al margen de las categorías tradicionales de la teoría del delito. La indeterminación de su contenido y los límites del concepto, son tanto su ventaja como su desventaja. La ventaja radica en su plasticidad. Todas las acciones dañosas pueden ser señaladas como inadecuadas socialmente. La desventaja radica en su incapacidad para soportar reflexiones jurídicopenales correctas, dado que le desconoce su primacía al Derecho vigente. En palabras de Kindhäuser (2018):

\footnotetext{
${ }^{8}$ Debido a la necesaria claridad e imparcialidad científica en la exposición de las posiciones teóricas, se evitará la división de las opiniones de autores que combinan diversos criterios.

${ }^{9}$ Esto vale especialmente cuando dicha calificación es utilizada no solo como conclusión de un análisis de reglas de comportamiento penales, sino que también como fundamento a favor de la impunidad de un comportamiento al menos prima facie típico.

${ }^{10}$ ver infra 1.1.4.3.
} 
Diffuse Hinweise auf Volk, Gesellschaft oder Alltagswertungen sind als solche völlig unzureichend, um strafbares Unrecht zu begrenzen [...]. Die Formel von der sozialen Adäquanz ist mithin ein inhaltsleerer Topos. Was sozial adäquat ist, richtet sich nach den Wertungen und Prinzipien des Rechts und nicht umgekehrt. (p. 57) ${ }^{11}$

La apelación a dicho concepto, merece las siguientes objeciones:

La primera es conocida. Tal como la calificación de una acción como neutral, la calificación de una acción como socialmente adecuada es esencialmente un problema de descripción de la acción (Schurmann Opazo, 2020, p. 270 y ss.; En este sentido especialmente Kindhäuser, 2018, p. 50-51; previamente Kindhäuser, 2010, p. 409 y ss.; de acuerdo Kudlich, 2004, p, 82, quien denomina a esa característica como dependiente-del-contexto). Una acción puede ser vista — bajo una determinada descripción - como socialmente adecuada y —bajo otra, con mejor información- como una acción típica. No existe un argumento plausible para darle una preferencia a este punto de vista por sobre el de las categorías propias del Derecho penal. La segunda y más importante objeción contra la teoría de la adecuación social, es la escasa determinación de la categoría - Bloy (1985, pp. 139 y ss., especialmente la nota al pie 59) la denomina como una fórmula vacía ; Beckemper (2001, p. 166) se refiere a este criterio como un concepto muy impreciso; en el mismo sentido; Frisch (1988, p. 296)-, incluso Hassemer (1995a, p. 46), que funda su propia teoría parcialmente en este concepto, afirma que la teoría de la adecuación social es una mezcolanza de lugares comunes, es por ello que intenta una investigación clarificadora en ámbitos profesionales. Distintos autores utilizan el concepto de forma dispar, dicho estado es descrito precisamente por las siguientes palabras de Kindhäuser (2018):

Das Schlagwort von der sozialen Adäquanz hat seither eine geradezu atemberaubende akademische Karriere durchlaufen und ist selbst in die höchstrichterliche Rechtsprechung eingegangen. Allerdings hat diese Entwicklung zu einem recht verschwommenen Kriterium des Unrechtsausschlusses geführt, dessen Erforderlichkeit, inhaltliche Präzision und deliktssystematische Lozierung kaum als auch nur halbwegs dogmatisch gesichert angesehen werden können. Während nach einer Auffassung (Jakobs) ,erlaubtes Risiko, Vertrauensgrundsatz, garantenbezogene Begehung und Regressverbot' als Explikationen der Sozialadäquanz zu verstehen sind, ist nach anderer Ansicht (Roxin) die soziale Inadäquanz allenfalls eine hermeneutische Richtlinie der Tatbestandsauslegung. ( $p$. 48) $)^{12}$

\footnotetext{
11 "Difusas referencias al pueblo, a la sociedad o a valoraciones cotidianas son completamente insuficientes para delimitar un injusto punible [...]. La forma de la adecuación social es por consiguiente un topos sin contenido. Lo que es socialmente adecuado es determinado por las valoraciones y principios del Derecho, y no al revés".

12 "El eslogan de la adecuación social ha recorrido una carrera académica impresionante y ya ha sido aceptada en la jurisprudencia de los tribunales superiores. En cualquier caso, dicho desarrollo lo llevó hacia un criterio jurídico difuso de exclusión del injusto, cuya necesidad, precisión del contenido y
} 
Lo que provoca que la adecuación social pueda no solo ser un fundamento para la atipicidad de una acción, sino que también la conclusión de otros fundamentos jurídicos, como por ejemplo de una causa de justificación. En este último sentido, la calificación de la acción como adecuada socialmente tiene el mismo valor que su calificación como impune y, por ello, no solo resulta irrelevante para el análisis, sino que también contra productivo, dado que el fundamento jurídico preciso y real para la impunidad de la conducta es disimulado bajo la calificación (fenomenológica o naturalística) de adecuación social (Kindhäuser, 2018, p. 53 y ss.). Así, no resulta claro cuál efecto tendría sobre una determinada conducta la calificación de ella como adecuada socialmente. Resulta evidente, que el más importante efecto es la exclusión del injusto y, por ello, la permisión de la conducta. Sin embargo, el carácter permitido de una acción puede tener dos sentidos diversos, uno débil y otro fuerte (fundamental Von Wright, 1974, pp. 31 y ss.; 1963, Nm. 10; Kindhäuser, 2018, p. 51 y ss.; Mañalich Raffo, 2015, p. 289 y ss.). Si el carácter permitido de una acción proviene de la ausencia de prohibición, ella se encuentra permitida en un sentido débil. Desde un punto de vista de la teoría de las normas, una acción se encuentra permitida en dicho sentido cuando ella no está prohibida bajo alguna de todas sus posibles descripciones. Si, al contrario, la autorización es el resultado de un fundamento jurídicamente reconocido — como, por ejemplo, el estado de necesidad—, entonces la acción está autorizada en un sentido fuerte. Así, una autorización débil no significa algo distinto que la imposibilidad de subsumir la acción bajo algún tipo penal y, con ello, la acción deber ser calificada como penalmente irrelevante, siguiendo la opinión de Roxin (1983, p. 310), la superficialidad es un riesgo debido al uso de criterios como cláusulas generales. De acuerdo a dicha distinción, resulta claro que Welzel ${ }^{13}$ (citado por Roxin, 1983, p. 306) utilizaba la expresión de esa misma forma irrelevante cuando clasificaba a todas las conductas - como el dar muerte a una mosca - en adecuadas e inadecuadas socialmente. Sin embargo, la teoría de la adecuación social ha sido utilizada también en otro sentido, al sostenerse que el carácter socialmente adecuado de una acción puede fundar la impunidad de un comportamiento típico -v. gr. la entrega de un pequeño y usual regalo de año nuevo a un cartero- (Roxin, 1983, p. 303), lo que implica esgrimir la concurrencia de una autorización fuerte, en tanto dicha calificación puede tener el poder de descartar una norma prohibitiva. Sin embargo, ese poder solo lo puede tener una causa de justificación reconocida (Roxin, 1983, pp. 305 y 313, rechaza ese efecto e intenta situar a la categoría como una restricción del tipo objetivo bajo la denominación del ámbito de protección de la norma), dado que la mera tolerancia a una actividad bajo una descripción en caso alguno puede implicar

ubicación sistemática en la teoría del delito escasamente puede ser apreciado. Mientras de acuerdo a una opinión (Jakobs) 'riesgo permitido', 'principio de confianza' y 'prohibición de regreso' son comprendidas como explicaciones de la adecuación social, de acuerdo a otra opinión (Roxin) la falta de adecuación social es una directiva hermenéutica de la interpretación de los tipos penales".

${ }^{13}$ Quien denomina también a la adecuación social como una "causa de justificación consuetudinaria". 
El tratamiento de las denominadas acciones neutrales a título de complicidad...

una autorización fuerte (Kindhäuser, 2018, p. 57 y. ss.; Von Wright, 1963, Cap., VII, Nm. 10).

\subsubsection{Comportamiento profesionalmente adecuado}

Una aplicación inmediata de la teoría precedente, se encuentra en la teoría de la adecuación profesional o del comportamiento profesionalmente adecuado desarrollada por Hassemer (1995a, p. 41 y ss.; Hassemer, 1995b, p. 81 y ss.), quien elaboró un ambicioso programa dogmático para investigar la punibilidad en ámbitos profesionales. Dicho programa, intenta superar la objeción de la indeterminación del parámetro bajo el cual se califica a una acción como adecuada socialmente. La investigación, se encuentra referida a la preconstrucción normativa de los ámbitos profesionales, los cuales pueden estar configurados por una compleja red de distintos tipos de normas y expectativas. Después de determinar la preconstrucción normativa del ámbito profesional, el segundo paso es la valoración de la compatibilidad de dichas reglas con las penales. Según Hassemer (1995b, p. 87), los ámbitos profesionales deben gozar de la presunción de que sus regulaciones profesionales se encuentran conforme a la regulación penal y que, en algunos casos y bajo determinadas circunstancias, dicha presunción puede ser derrotada.

Una posición similar, ocupa el análisis de Philipowski (1983, pp. 142 y ss.) sobre la exclusión de la punibilidad de funcionarios de un banco en relación a una transferencia anónima de fondos al extranjero que es funcional a una evasión tributaria, dado que ellos han ceñido su conducta a las normas vigentes $y$, con ello, han actuado de forma socialmente adecuada y en el marco del riesgo permitido. Una línea cercana sigue Meyer-Arndt (1989, p. 287) cuando afirma que la acción del tercero no debe ser punible si su contribución se ajusta a la conducta del autor, en la medida que ella sea legal y —más allá del posterior delito del autor principal- ella tenga un sentido económico, social o individual independiente.

Pese a que Hassemer intenta superar la indeterminación a través de la consideración a la preconstrucción de estos ámbitos especiales, dicho intento merece al menos dos críticas: (i) no resulta claro cómo se constituye la adecuación profesional. Hassemer se refiere a la preconstrucción normativa de los ámbitos profesionales. Sin embargo, es imprescindible formular una distinción entre normas propiamente tales y meras regularidades, dado que solo las normas pueden tener influencia sobre la valoración penal de una acción. Lo habitual no puede erigirse en un baremo de lo correcto (Amelung, 1999, p. 9 y ss.). (ii) La segunda objeción, se refiere al efecto que tiene la calificación de una acción como profesionalmente adecuada sobre su valoración como punible. Resulta dudoso que el cumplimiento de las reglas profesionales pueda tener el efecto de excluir la punibilidad de una conducta y, en caso de que ello efectivamente se sostenga, cómo podría ser legitimado dicho efecto. Para evaluar dicho efecto, deben ser hechas ulteriores distinciones sobre el tipo de normas a las 
que se hacen referencia, distinguiendo entre origen, jerarquía, función y contenido de las normas (Schurmann Opazo, 2020, p. 270 y ss.). Esta teoría, provoca especiales inseguridades desde que el efecto más interesante de ella no radicaría necesariamente en la exclusión del injusto, sino que, en su relevancia procesal, esto es, en señalizar a las normas y regularidades de los ámbitos profesionales como un ámbito relevante de investigación para los delitos desarrollados en dicho ámbito. Pese a que esta "función indiciaria" puede ser útil, ello prueba que la teoría de la adecuación profesional no está en condiciones de fundar una impunidad general para las acciones neutrales (Amelung, 1999, p. 11), sino que solo de ofrecer una senda de investigación normativa a favor de ella (Otto, 2001, p. 436).

\subsubsection{Restricción objetiva de la punibilidad a una "relación de sentido delictiva"}

El criterio de la "relación de sentido delictivo" del acto se encuentra aquí referido únicamente a su fase objetiva, y debe ser diferenciado de la teoría mixta (objetiva-subjetiva) de Roxin, la cual utiliza la misma expresión ${ }^{14}$. Una explicación suficiente se encuentra en Frisch (1988, p. 298).

En la búsqueda de la determinación del comportamiento típico que funde el injusto de acción, y con ello pueda delimitar la prestación de ayuda lícita de la ilícita, Frisch (1988, p. 295 y ss.) y en términos similares Kudlich (2004, p. 99 y ss.) sostienen que una acción de apoyo debe exhibir una suficiente y clara relación de sentido delictiva - desde una perspectiva objetiva ex ante- para que pueda ser afirmada su punibilidad. Con dicho requisito Frisch (1988) destaca la relevancia del efecto de filtro propio de la imputación objetiva, desde que la referida relación destacaría que la creación o el aumento del riesgo debe ser también desaprobado legalmente. Robles Planas (2003, p. 291 y ss.) reflexiona desde el mismo punto de vista que Frisch y afirma que el comportamiento típico del cómplice se encuentra contenido en el riesgo delictivo interno. Ese riesgo delictivo interno puede ser identificado a través de dos criterios: (i) la lesión de deberes (de garantía) preexistentes; (ii) la configuración del comportamiento como parte del hecho. El problema fundamental radica en el segundo criterio, ya que confirma que la imputación del delito a título de complicidad es necesariamente contextual y referida a la acción principal del autor. Hurd (2001, p. 319 y ss.) parece tener una comprensión similar de los deberes del partícipe, al afirmar que no existe un deber moral de evitar prestarle ayuda a otro que se pueda formular a partir de normas directas o primarias, ella califica a la prohibición tanto de acciones neutrales como profesionales como propio de un sistema represor (no libre). Dicha constitución del injusto puede ser fundada a través de relaciones con sentido delictivo, deberes de garante, deberes de solidaridad -Wohlers (2000, p. 173) esboza una solución con similares criterios, esto son, deberes de solidaridad y de garantía de protección-, y reglas y principios del estado de necesidad. Y esos funda-

\footnotetext{
${ }^{14}$ ver infra 1.3.1.
} 
mentos, a su vez, deben ser ponderados con otros principios penales, como el de ultima ratio y proporcionalidad, de modo de fundar una prohibición extraordinaria de la libertad de acción como la que supone sancionar una acción auxiliar o de apoyo como complicidad. Constituyen criterios relevantes para ello la exigencia de (i) una relación espacio-temporal estrecha con la lesión posterior y (ii) la adaptación de la acción de apoyo a los deseos del autor principal. Las actividades profesionales tienen a su favor la presunción de actuar conforme a Derecho, dado que ellas están integradas en el entramado social aceptado y, en ese sentido, la sanción penal de prestaciones cotidianas tendría una alta carga de legitimación (en este sentido también Seher, 2009, p. 795). Así, por medio de dichas consideraciones podría ser desarrollada una solución para el problema de la punibilidad de las acciones neutrales. En este sentido, Frisch (2002, p. 557) rechaza un aumento del riesgo suficiente cuando el autor podría procurarse la ayuda necesaria de forma legal previo a la fase de ejecución del delito, dado que dichas acciones conservan todavía de forma suficiente su sentido conforme a Derecho. Frisch (1988, pp. 296 y 297) utiliza aquí el ejemplo -utilizado por Roxin y descrito previamente- de quien entrega materiales para una empresa que produce infringiendo las normas medioambientales ${ }^{15}$. La excepción proviene aquí de eventuales deberes, tanto de garantía como de solidaridad de acuerdo con -por ejemplo- los parágrafos $\S \S 138,323$ c StGB (1871). Una regla adicional de creación de riesgo no permitido en el sistema de Frisch (1988, p. 331 y 332.) radica en la prestación de ayuda a través de la desviación de las reglas (extrapenales) de un determinado subsistema, como lo son por ejemplo las reglas tendientes a disminuir el riesgo de circulación de productos peligrosos como las armas. Sin embargo, no constituye necesariamente un comportamiento permitido la observación de dichas reglas, dado que ese sería el caso solo si el seguimiento de la regla constituye un medio idóneo para la reducción del riesgo. Frisch (1988, pp. 90 y 91) analiza la función y efecto de esa regla, en esta parte su teoría, se asemeja a la exclusión de la punibilidad de los comportamientos profesionales ${ }^{16}$. En un sentido similar entre nosotros, ver Contreras Chaimovich (2018, p. 397 y ss.).

La principal objeción a la solución desarrollada por Frisch, radica en lo complejo de su construcción dependiente de excepciones y contra excepciones y caracterizada por la apelación a distintos principios generales (Kudlich, 2004, p. 99 y ss.), es por ello que esta teoría tiene escasa operatividad en casos concretos. Esa compleja construcción proviene del proyecto normativo al que subyace: la determinación del comportamiento típico del cómplice, a través de su propia creación de riesgo no permitido. Sin embargo, es incorrecto valorar una contemplación aislada de la acción de complicidad, dado que su injusto se constituye precisamente en la conexión de la acción principal del autor, lo que determina el carácter accesorio de la complicidad.

\footnotetext{
${ }^{15}$ La posibilidad de utilizar cursos causales hipotéticos y de reserva es revisado y excluido en infra 1.1.4.2.

${ }^{16}$ Es, por ello, que son válidas aquí también las críticas formuladas en el apartado supra 1.1.2
} 
La comprensión del injusto del cómplice desde el punto de vista de la teoría de la imputación y la distinción entre acción principal y acción auxiliar, permite abandonar la noción de realización de riesgo jurídicamente desaprobado como requisito del injusto de acción. Para la distinción entre acción principal y acción auxiliar a partir de la interpretación de la acción como un comportamiento atributivamente intencional, ver Brennenstuhl (1975, p. 217 y ss.; 1980, p. 60 y ss.). Fundamental para comprender las implicancias de una correcta comprensión del carácter accesorio de la complicidad, ver Bloy (1985, p. 290 y ss.), Vogel (1993, p. 80 y ss.), y Kindhäuser (1997, pp. 272275). Frisch se esfuerza en buscar una legitimación de la prohibición del comportamiento del cómplice (el cual normalmente se mueve dentro del ámbito conforme a Derecho) en principios generales, desconociendo que dicha legitimación proviene directamente de la prohibición prevista en el StGB $(1871, \S 27)$.

Otra crítica que merece la teoría, es la confusión conceptual en la que incurre entre los delitos de omisión propia previstos en los $\S \S 138,323$ c StGB (1871) y la punibilidad del cómplice a partir del § 27 StGB (1871). Dichas normas responden a distintos fundamentos y se refieren a distintos tipos de comportamientos, los cuales pueden satisfacer simultáneamente y con completa independencia distintos supuestos de hecho previstos por las reglas de comportamiento, en contra de la apelación a reglas generales del estado de necesidad y solidaridad mínimas, aboga Kindhäuser (2007a, p. 369 y ss.) y agrega un ejemplo aclaratorio. En relación con la posibilidad de interpretar una acción desde diversas perspectivas (normativas), ver Schurmann Opazo (2020, p. 270 y ss.). La existencia de un mandato de solidaridad mínima en un determinado caso, no puede simplemente cambiar el baremo para determinar el alcance de la prohibición de prestar colaboración a otro para que cometa un delito.

\subsubsection{Otras restricciones en el nivel de la imputación objetiva y la aplicación de la prohibición de regreso}

Mientras las teorías precedentes intentan una restricción de la acción de complicidad punible, otras opiniones afirman que la solución del problema debe ser encontrado en la imputación del resultado (Amelung, 1999, p. 14). Sin embargo, la teoría de la imputación objetiva ofrece muchas posibilidades para encontrar una solución sin embargo, esas extensas posibilidades no son precisamente una ventaja. Para una crítica a la teoría de la imputación objetiva resulta fundamental ver Kindhäuser (2007b). Otra crítica, tanto desde sus fundamentos como por sus insostenibles consecuencias se encuentra en Aichele (2011)-. Es por ello que se hallan en el mismo nivel teórico diversos criterios.

1.1.4.1. La creación de un riesgo jurídicamente desaprobado como criterio principal en la construcción de Schall

La capacidad aclaratoria del criterio de incremento del riesgo es discutida por Schall (2002) dentro de la teoría de la imputación objetiva, dado que comportamien- 
tos cotidianos pueden facilitar - en un caso concreto- la comisión de un hecho delictivo. Schall (2002, p. 144 y ss.) propone el tratamiento del problema trasladando la evaluación de la imputación al segundo requisito o estadio del análisis de la teoría de la imputación objetiva, esto es, el carácter jurídicamente desaprobado del riesgo creado. Para dichos efectos, establece dos criterios: (i) la creación de un riesgo jurídicamente desaprobado a través de la solidaridad con el autor y (ii) la lesión de deberes legales de acción. El primer criterio fue desarrollado por Schumann (1986, p. 49 y ss.) y radica no solo en la aprobación interna del cómplice, sino que principalmente para casos de comportamientos colusivos. Para Schumann (1986, p. 54 y ss.) la solidaridad con el autor no es un criterio restrictivo de la imputación objetiva, sino que el fundamento penal de la participación, el cual puede tener un efecto especialmente restrictivo para la punibilidad de acciones neutrales ${ }^{17}$. El segundo criterio se refiere al interés en la libertad general de acción, fundada en el derecho al libre ejercicio de la profesión, la cual debe ser ponderada (en términos similares a la propuesta teórica de Frisch) con el injusto de acción y el bien jurídico afectado.

Mientras el segundo criterio merece las mismas objeciones que la teoría de Frisch, el primero (solidaridad con el autor) contendría un requisito general no escrito de la punibilidad del cómplice, lo que constituye precisamente una objeción en su contra. Dicho requisito no es fácilmente conciliable con el tenor literal de la ley y, adicionalmente, no entrega criterios claros para determinar cuándo se presenta una situación de solidaridad, sino que solo indicios para identificar su ausencia (Kudlich, 2004, p. 114).

1.1.4.2. La libre y general disponibilidad de una prestación y la consideración de la relación espacio-temporal entre la entrega y la acción principal como criterios normativos de carácter restrictivo propios de la imputación objetiva

Puppe (1998, p. 27; 2017, N. 173) sostiene como restricción, también en el nivel de la imputación objetiva, que tanto la disponibilidad general de objetos y prestaciones como el tiempo que media entre la realización del acto de colaboración y la ejecución del hecho delictivo posterior, deben ser criterios decisivos para evaluar punibilidad de la conducta a título de complicidad. Dado que una prohibición genérica de dicha prestación no constituye un medio idóneo para mejorar las posibilidades de conservación del bien jurídico, la evaluación del carácter prohibido de la conducta debe ceñirse a los factores que contextualizan dicho aporte -este es también el primer criterio en la construcción de Wohlers (2000, p. 173)-. En virtud de dicho argumento, no solo debió haber sido declarado como lícito el suministro de pan en el denominado "caso del burdel" (1906, RGSt 39 44), sino que también el suministro de vino -ver la exposición de las sentencias en Meyer-Arndt (1989, p. 282 y ss.) y Lesch (2014, p. 453 y ss.), desde una perspectiva histórica con referencia a las deci-

\footnotetext{
${ }^{17}$ Véase especialmente los ejemplos relativos al problema de las acciones "neutrales".
} 
siones del Reichsgericht (RG) ${ }^{18}$ y el Schweizerisches Bundesgericht (Schweiz BGE) ${ }^{19}$, vease Rackow (2007, p. 281 y ss.)-. Al contrario, las armas y el veneno no son objetos generalmente disponibles y, por ello, su prestación puede ser integrado en un comportamiento delictivo si la entrega es realizada infringiendo su regulación. Al mismo resultado arriba Greco (2015, p. 4), cuando afirma que la negación del cómplice a colaborar con prestaciones intercambiables que se encuentran generalmente disponibles, no produce efecto positivo alguno para la protección del bien jurídico. Sin embargo, dicho criterio es válido especialmente cuando el hecho punible todavía no es inminente. Schumann (1986) ha desarrollado un criterio similar denominado "cercanía al hecho", en sus palabras: "der sozialpsychologisch gefährliche Eindruck der Solidarisierung [kann] schon durch die besondere ,Tatnähe' entstehen" (pp. 57 y 58). Al contrario, cuando el hecho punible es inminente, los fundamentos arriba señalados para la permisión del suministro del instrumento delictivo no concurren, dado que en ese estadio un instrumento generalmente disponible puede ser decisivo y la realización del hecho punible depender simplemente de un distribuidor confiable (Puppe, 2017, no. 174).

La objeción que habitualmente es levantada en contra de estos criterios, se encuentra referida a que situar la atención en la disponibilidad de un bien implicaría considerar cursos causales hipotéticos ilegítimos para sostener que un comportamiento antijurídico es impune (Roxin, 2003, p. 210; de acuerdo Beckemper, 2001, p. 164). En este sentido, se sostiene que la disponibilidad general de bienes y servicios debiese ser irrelevante para excluir la imputación penal. Kindhäuser (2007a, p. 367) rechaza esta objeción, argumentando que un criterio formulado en esos términos no recurre ilegítimamente a cursos causales hipotéticos, sino que se mueve dentro del ámbito normativo de los principios de la imputación objetiva (en el mismo sentido también Greco, 2015. p. 5; Bloy, 1985, p. 274 y ss). Una argumentación similar sigue Löwe-Krahl (1995, pp. 205 y 206), al sostener que los cursos causales hipotéticos pueden erigirse como criterio decisivo en el marco de la imputación objetiva, dado que a través de contribuciones estandarizadas no se realiza un riesgo jurídicamente desaprobado para el bien jurídico (Kudlich, 2004, p. 366). Al contrario, si el aporte constituye una adaptación al plan delictivo del autor, entonces se verificaría una complicidad punible. Otra objeción en contra de la propuesta teórica de Puppe es levantada por Kudlich (2004, p. 456), al afirmar que el momento decisivo no puede ser el de la prestación de la colaboración, sino cuándo ella es utilizada. Roxin (1995, pp. 514 y 515) rechaza también este criterio apropósito de la crítica que le formula al criterio de la "cercanía al hecho" desarrollado por la teoría de Schumann (1986). Pese a que esa crítica tiene a su favor el carácter accesorio de la complicidad, es imprescindible enfatizar que la acción debe ser vista al momento de su ejecución como una prestación de ayuda, dado que dicho elemento es parte de la conducta prevista en la

\footnotetext{
${ }^{18}$ Tribunal del Rey

${ }^{19}$ Tribunal Supremo Suizo
} 
norma que extiende la punibilidad sobre la complicidad y, al mismo tiempo, se erige como el fundamento para atribuir responsabilidad penal al cómplice por el delito cometido por otro.

\subsubsection{La apelación a la prohibición de regreso como límite decisivo para la punibili- dad del partícipe}

Es bastante habitual utilizar la distinción entre la nueva y la vieja teoría de la prohibición de regreso. Así, por ejemplo, Kudlich (2004, p. 376 y ss.). De acuerdo a Roxin (1989, p. 177 y ss.), la antigua teoría de la prohibición de regreso postula que la cooperación imprudente en una realización dolosa y plenamente responsable de un tipo penal es impune. Aquí solo es tratada la nueva teoría, dado que ella es situada como una consecuencia de la teoría de la imputación objetiva. En este sentido, Jakobs (1977) afirma que la prohibición de regreso es el reverso de la accesoriedad y, con ello, también de la creación de riesgo no permitido. Sin embargo, esta nueva formulación de la teoría de la prohibición de regreso tiene una pre-historia. Previamente en este sentido ver Naucke (1964, p. 427 y 428). Sobre la antigua y nueva teoría de la prohibición de regreso ver también Bloy (1985, p. 130 y ss.). Entre nosotros, un interesante análisis de evolución y actualidad de la teoría de la prohibición de regreso se encuentra en Ananías Zaror (2010).

La apelación a la nueva teoría de la prohibición de regreso, es utilizada para restringir la imputación objetiva de la acción colaborativa con el resultado lesivo. Jakobs (1977 y 2014) ${ }^{20}$ basa su opinión en su teoría general del hecho punible y, especialmente, en el concepto de competencia (Jakobs, 1977, p. 1 y ss.; Jakobs, 1996, p. 253 y ss.; Jakobs, 1993). Es competente por la evitación de un resultado antijurídico la persona que, para el caso de una omisión, sería garante de la evitación del resultado lesivo. La moderna teoría de la prohibición de regreso funciona aquí como la contracara de la competencia (Lesch, 2014, p. 463) o la accesoriedad (Jakobs, 1996, p. 265), es decir, la incompetencia por el comportamiento de otro. Con palabras de Jakobs (1996): "Das Regreßverbot hebt bestehende Pflichten nicht auf, sondern erklärt nur das isolierte aktuelle Verhalten als per se nicht zur Haftung hinreichend" ( $p$. $263)^{21}$, una formulación similar se encuentra Jakobs (1993, p. 698). Para fundar la responsabilidad, es necesario que sea posible sostener una competencia del colaborador sobre el resultado, y dicha competencia existiría cuando el comportamiento exprese una comunidad normativa entre el autor y el colaborador, esto es, si existe un sentido conjunto de la acción (Jakobs, 1977, p. 25), un camino similar aparenta seguir

\footnotetext{
${ }^{20}$ Resulta evidente apreciar una evolución en la teoría de Jakobs entre los artículos sobre la prohibición de regreso de 1977 y la teoría de la participación de 2014. En primer lugar, porque en la primera versión se considera con especial relevancia el plan delictivo del autor, importancia que posteriormente decrece, $y$, en segundo lugar, porque en sus escritos posteriores gana en relevancia la idea de rol. Es por ello que el propio Jakobs denomina a su teoría previa como una solución orientada hacia un claro sentido subjetivo. La propuesta teórica expuesta aquí se basa principalmente en su teoría posterior. 21 "la prohibición de regreso no deroga deberes preexistentes, sino que declara que el comportamiento actual aislado no es suficiente per se para fundar responsabilidad".
} 
Duff (1990, p. 175 y ss.), pese a que la discusión anglosajona continúa bajo la idea de intencionalidad de quien presta la colaboración, cuando de la mano de casos equivalentes argumenta que el rol de ciudadano no puede implicar un deber de prevenir el daño a terceros. Esta intencionalidad penalmente relevante solo puede ser imputada si el colaborador hace algo más que su trabajo normal. El trasfondo de la prohibición de regreso, radica en que esta limitación de competencias por el comportamiento de otro facilita los contactos anónimos en una sociedad compleja y, con ello, propicia una consideración aislada de la acción, a menos que ella en si misma contenga un injusto. En cualquier caso, la determinación de ese sentido conjunto de la acción debe tener lugar tomando en consideración el contexto de la acción (Jakobs, 2014, p. 17). Dicha accesoriedad es independiente del dolo y la imprudencia, razón por la cual Jakobs rechaza una solución al nivel del tipo subjetivo. Consecuentemente con los fundamentos de su teoría, Jakobs (1996, p. 261) sostiene que una sociedad con división del trabajo y con un intercambio altamente complejo de información, bienes y servicios, solo puede estar regida por el sentido objetivo de los contactos sociales, con otras palabras, y siguiendo a Luhmann, Lesch (2014) sostiene: "Selektive, Komplexität und Kontingenz abbauende Erwartungsstrukturen sind also eine Lebensnotwendigkeit" (p. 466) ${ }^{22}$. Dicho sentido objetivo es limitado a través de la descripción de las expectativas sociales de los roles previamente constituidos. Es por ello precisamente que cualquiera que actúe dentro de su rol social, no podría realizar la descripción de una conducta típica. Para determinar la utilidad de su teoría, Jakobs propone criterios que permitan evaluar la posibilidad de disociar a la acción de complicidad del delito posterior. Sin embargo, de acuerdo con la última opinión de Jakobs (2014, p. 33 y ss.), el carácter delictivo de una prestación de ayuda puede ser imputado no solo a través del traspaso de los límites del rol social, sino que también a través del entorno en el cual la acción es ejecutada y cómo ella se ajusta al plan delictivo del autor. De acuerdo con esta formulación, el contexto de la acción es considerado crecientemente, dado que dicho contexto puede cambiar el significado de todo comportamiento. Es por ello que la prohibición de regreso rige especialmente en la etapa de los actos preparatorios, en donde la conexión de la acción colaborativa con el hecho delictivo posterior es débil o menos evidente (Jakobs, 2012, p. 80 y ss.).

Próximo a la postura teórica previa de Jakobs, Lesch (2014) representa en la actualidad dicho punto de vista sobre el problema de las acciones profesionales al afirmar que "'Berufstypisches bzw. ganz allgemein ,rollenadäquates' Verhalten ist also überhaupt keine Besonderheit und insbesondere kein eigenständiger Topos der objektiven Zurechnung" (p. 468) ${ }^{23}$. Él identifica dos constelaciones de casos que deben ser distinguidos: unidad normativa-organizativa y unidad únicamente normativa.

22 "Selectividad, complejidad y contingencia desestabilizadora de estructuras de expectativas son también una necesidad vital".

23 "Tanto comportamientos profesionales como generalmente adecuados a un rol no constituyen una especialidad y, sobre todo, no constituye un asunto independiente para la imputación objetiva". 
La primera posibilidad, requiere que quien colabora con el hecho ajuste su comportamiento a una organización delictiva ajena. La segunda alternativa, por su parte, se verifica cuando quien colabora lesiona deberes de seguridad especialmente previstos. Solo en ese caso puede ser ignorada una -generalmente válida- prohibición de regreso, y fundarse así la punibilidad de la conducta (Lesch, 2014, p. 469).

La mayoría de las críticas se dirigen en contra de los resultados de la teoría de la prohibición de regreso, en los términos sostenidos por una postura previa de Jakobs. Dicha teoría, pretende sostener una fuerte barrera objetiva de la punibilidad de las acciones previas a la principal, donde la conformidad con el rol de una acción entrega una razón para la atipicidad de la conducta. El problema fundamental de esta postura, es que pretende la aplicación de principios generales sin atender al carácter accesorio de la complicidad (Kudlich, 2004, p. 92), lo que la lleva necesariamente a una solución insatisfactoria del problema, especialmente cuando un contexto delictivo es relativamente claro. Pese a que la postura actual de Lesch (2014) todavía merece esa crítica, ello no aplica para la nueva postura de Jakobs en la materia, quien a través de la postulación de un criterio "dependiente del contexto" y la consideración del entorno apreciablemente delictivo, puede superar dichas críticas. Un buen ejemplo de este desarrollo, se encuentra en la descripción de la compra de un cuchillo de mesa bajo distintas circunstancias. Eso puede ser visto como una compra normal o como una colaboración en un homicidio cuando el receptor no juega solo el rol de receptor de cuchillos, sino que también uno de asesino (Jakobs, 2003, p. 566). Sin embargo, persiste el principal problema de la teoría: la consideración de un punto de vista irrelevante para la imputación penal como punto de partida del análisis. ¿Por qué podrían tener mayor relevancia las expectativas relativas a la concreta profesión del autor que las propias de un ciudadano fiel al Derecho?. Nuevamente, se muestra que el problema radica en la errónea determinación del objeto de la imputación y, con ello, de la descripción de la acción (Kindhäuser, 2010, p. 411; Schurmann Opazo, 2020, p. 270 y ss.).

Sin perjuicio de que este no es el lugar para exponer las críticas que generalmente se le formulan a la construcción general de Jakobs (Kudlich, 2004, p. 90 y ss.; de especial relevancia resulta también revisar Wohlleben; 1996, p. 90), es importante notar que la apelación a la prohibición de regreso como fundamento de la impunidad, debido a la incompetencia por el comportamiento de otro, constituye un criterio discutido. El contenido y función de esa nueva forma de concebir la prohibición de regreso no es del todo claro y, por ello, cae dentro de la crítica que previamente se ha formulado en contra de la postulación de criterios jurídicos difusos como herramienta teórica de delimitación de la punibilidad de una conducta ${ }^{24}$. En los términos de Jakobs, la prohibición de regreso constituye la exclusión de las condiciones pre-

\footnotetext{
${ }^{24}$ Es por ello que esta teoría padece similares críticas a las formuladas en contra de la teoría de la adecuación social. Ver supra 1.1.1.
} 
vias de un suceso del ámbito de responsabilidad penal potencial (Kindhäuser, 2015a, p. 129). Si bien dicha responsabilidad es afirmada prima facie por la concurrencia de una relación causal, ella puede ser posteriormente descartada en base a criterios normativos. Pese a que la teoría de la prohibición de regreso -bajo la construcción de Jakobs- constituye un criterio de la imputación objetiva dentro del ámbito de la participación punible, ella aparenta fundar más bien la imposibilidad de participar en un delito, dado que la creación de un riesgo no permitido requiere la ausencia de una prohibición de regreso. Especialmente claro en este sentido es Jakobs (2012, pp. 80 y 81). Roxin (1989), concuerda con él, cuando afirma que la mayoría de los casos de prohibición de regreso pueden ser excluidos según los principios generales de la teoría de la imputación y bajo el punto de vista del riesgo permitido. Con otras palabras, solo se puede apelar a una prohibición de regreso cuando el comportamiento carece de relevancia delictiva (Jakobs, 2014, p. 29 y ss.), de modo que la prohibición de regreso no sería más que el reverso de la responsabilidad penal para un tercero, debido a la ausencia de imputación objetiva de la acción delictiva a su respecto. Es por ello que se debe concordar con Kudlich (2004, p. 374 y ss.) cuando afirma que la prohibición de regreso no sería un instrumento de imputación, sino que el resultado de un proceso de imputación, de modo que el concepto de prohibición de regreso no puede entregar algo más que una etiqueta carente de contenido autónomo.

\subsection{Propuestas de interpretación restrictiva de la regla que extiende la responsabilidad penal al cómplice}

Pese a que las opiniones aquí expuestas tienen en común con las precedentes la convicción de que la solución del problema debe ser alcanzada fundamentalmente en un nivel objetivo, la diferencia radica en los puntos de partida de sus acercamientos al problema. Mientras las posturas precedentes apoyan una solución dentro de la categoría de la imputación objetiva, las teorías que se exponen en este apartado sostienen que la solución al problema de las denominadas acciones "neutrales" debe ser encontrada en la teoría de la participación y en las normas legales que regulan la punibilidad de la complicidad.

\subsubsection{La interpretación restrictiva de la regla de comportamiento del cómplice por medio del criterio cuantitativo relativo al carácter esencial de la prestación}

Wiegand (1998), opina que el estado de la discusión es insatisfactorio debido a la falta de consideración de los fundamentos estructurales de la punibilidad del partícipe en la formulación de los criterios. Con un acento en el carácter accesorio de la complicidad, destaca Wiegand (1998) su merecimiento de pena afirmando que "Als Gehilfe ist strafbar, wer vorsätzlich eine Handlung zur Unterstützung der rechtswidrigen Tat eines anderen vornimmt, sofern sich seine Handlung tatsächlich fördernd auf die aufgeführte oder zumindest versuchte Haupttat auswirkt" (p. 207 y 
$208)^{25}$. Dado que no ha sido encontrado un criterio cualitativo más idóneo, se plantea al carácter "esencial" -similar, importante o esencial; Schild (2017, Nm. 3)- de la acción de colaboración como un criterio cuantitativo derivado de la estructura de la complicidad, de modo que, a partir de dicho criterio, podrían ser excluidos del ámbito de lo punible aportes mínimos y fungibles y, con ello, ver satisfecha la necesidad político-criminal de descriminalizar aportes "inofensivos" al hecho punible. En este ámbito, se encuentran las prestaciones generalmente disponibles ${ }^{26}$ y los casos de desconexión entre el aporte y la decisión delictiva posterior del autor (Wiegand. 1998 , pp. 210 y 211 ).

La objeción que fácilmente puede ser levantada en contra de esta postura, es apreciada por el propio Wiegand (1998, p. 218). Los criterios cuantitativos tienen en general la ventaja de la elasticidad, pero - al mismo tiempo - tienen la desventaja de una escasa previsibilidad en sus resultados. Es por ello que son siempre preferibles los criterios cualitativos. La principal virtud de la propuesta teórica de Wiegand (1998) consiste en la correcta localización de la problemática en el ámbito dogmático de la complicidad, y mediante el examen del tenor literal de la regulación legal.

\subsubsection{La propuesta interpretativa del elemento típico colaboración como medio decisivo para delimitar la subsunción de conductas punibles a título de compli- cidad}

Kindhäuser (2007a, p. 357) propone también una investigación dentro de los límites internos de la punibilidad del cómplice, afirmando como criterio general que la prestación de ayuda debe ser en alguna forma útil a la acción principal para determinar -de una forma objetiva- el comportamiento prohibido a título de complicidad. El primer paso del programa de investigación, requiere reconocer que ayuda es un concepto cuyo significado se encuentra anclado a una relación intencional medio-fin (Kindhäuser, 2007a, p. 360). Con otras palabras: colaboración debe ser entendida como un medio necesario para alcanzar el fin delictivo del autor (Kindhäuser, 2015b, p. 384). El concepto de colaboración requiere alcanzar un determinado fin y, con ello, su calificación presenta una naturaleza hipotética. Se trata de una acción que garantiza, prepara o procura mantener la capacidad para ejecutar la acción principal y, de esa forma, que ella no fracase. Kindhäuser (2007a), utiliza aquí la terminología habitual de la teoría de la autoría y participación: "Ist die Haupttat des Täters durch die Beherrschbarkeit ihres Verlaufs hinsichtlich Gestaltung und Entscheidung geprägt, so wird durch eine wirksame Beihilfe die Intensität der Tatherrschaft gestei-

\footnotetext{
25 “Es punible como cómplice quien realiza una acción dolosa para apoyar un hecho antijurídico de otro, en tanto su acción de hecho tenga un efecto colaborador con la acción principal ejecutada o al menos intentada".

${ }^{26}$ La posibilidad de utilizar causas de reserva o cursos causales hipotéticos es revisado y descartado en el apartado 1.1.4.2.
} 
gert und damit das Risiko, dass die Tat im Sinne des Täters gelingt, erhöht" (p. 361) ${ }^{27}$. El carácter útil o colaborador de la acción, debe estar presente de forma objetiva ya desde el momento de su aporte para la ejecución de una o más hechos determinados -si las acciones son externamente neutrales o no, no tiene relevancia alguna. Kindhäuser (2015b, p. 384)- .Por medio de dicho requisito, pueden ser excluidas del concepto de colaboración diversas contribuciones previas. Allí donde no existe finalidad, no es posible que exista colaboración. Al mismo tiempo, cuando es posible apreciar una cisura entre la recepción de aportes con fines legales y la decisión posterior autónoma del autor, entonces ese aporte no puede ser visto como complicidad debido a la ausencia de conexión en una relación delictiva de medio a fin entre dicho aporte y el hecho posterior (Kindhäuser, 2007, p. 363).

Es precisamente por dicha razón que Kindhäuser (2015b, p. 384) —quien en este punto sigue a Puppe ${ }^{28}$ - afirma que las prestaciones realizadas en el estadio de los actos preparatorios no constituyen complicidad, si dichas prestaciones se encuentran disponibles para el autor fácilmente y de forma legal. Con el comienzo de la fase ejecutiva se concretizan el marco de condiciones con las que actúa el autor, en donde objetos y prestaciones generalmente disponibles pueden ser de ayuda para aumentar las posibilidades de éxito desde la perspectiva del autor y su plan. Aquí solamente puede erigirse como criterio decisivo la relación de inmediatez con la realización del hecho, de modo que dicha inmediatez hace manifiesta la necesidad de la prestación de ayuda para alcanzar el fin delictivo del autor (Kindhäuser, 2007a, pp. 368 y 369$)$.

Para esclarecer este argumento, Kindhäuser (2007a) recurre a la regla prevista en el StGB (1871, § 224 inc. 1, no. 2) que agrava la responsabilidad penal por el delito de lesiones corporales, si ellas son causadas mediante armas $u$ otros instrumentos peligrosos. De acuerdo con dicha regulación, mientras que las "armas" son un medio lesivo per se, presentando esta característica de forma abstracta, instrumentos peligrosos son objetos que obtienen su peligrosidad mediante el determinado y concreto uso de estos. Dicho criterio objetivo, puede ser útil para distinguir entre comportamientos de colaboración punibles de aquellos que no lo son. Mientras la entrega de un arma, sin referencias adicionales a un determinado contexto, puede ser visto objetivamente como complicidad de una lesión corporal posterior -esto vale no solo para medios ilícitos, sino que también para medios lícitos e idóneos. Kindhäuser (1997, p. 273 y ss.) utiliza como ejemplo un informe pericial falso sobre el supuesto valor de una piedra preciosa, pese a que ello constituye solo una mentira escrita no punible-, no se puede arribar a la misma conclusión respecto de un pañuelo de seda,

\footnotetext{
27 "Si el hecho principal del autor está impregnado por la conducción del curso causal, en relación a su configuración y decisión, entonces la intensidad del dominio del hecho es elevada a través de una complicidad efectiva $y$, con ello, se eleva el riesgo de que el hecho punible resulte en el sentido deseado por el autor".

${ }^{28}$ Ver 1.1.4.2.
} 
el cual podría ser contextualmente útil para estrangular a una persona (Kindhäuser, $2007 a$, p. 364 y ss. $)^{29}$. En un caso de tales características, resultaría de gran dificultad sostener que el vendedor del pañuelo de seda habría vendido un instrumento peligroso o realizado un acto de colaboración para una lesión corporal posterior, dado que no es la venta, sino que el posterior uso que de él se hace, lo que lo constituye en un objeto penalmente relevante. De esta forma, si bien ambos objetos son medios de ayuda para la acción específica posterior, solo puede ser afirmada respecto del arma que ella contiene dicha característica con independencia del momento de su uso (Kindhäuser, 2015b, p. 384).

Los fundamentos de dicha exclusión, se encuentran en la distinción entre dos tipos de condiciones causales necesarias para aclarar un determinado suceso dañoso. Mientras que solo una condición suficiente puede realizar el tipo penal, al mismo tiempo las restantes condiciones (necesarias mas no suficientes) de dicho evento pueden ser vistas como condiciones auxiliares (Kindhäuser, 2007a, p. 367). Sin embargo, es posible realizar una indagación adicional dentro del campo causal del autor. Por una parte, habría condiciones que sirven de base para una aclaración causal, es decir, que son designadas como condiciones dadas para una aclaración causal de un suceso dañoso. En dicho grupo se encuentran no solo condiciones naturales (v. gr. el oxígeno para el origen de un incendio), sino que también acciones humanas que constituyan condiciones esperables en un determinado momento. Por otra parte, existen condiciones que son inesperadas, como aquellas que provienen, por ejemplo, de una contravención de una expectativa normativa. Dichas condiciones inesperadas, deben ser relevantes para fundar la atribución de responsabilidad por la producción de un resultado injusto, pudiendo constituir actos de colaboración punibles a título de complicidad (Kindhäuser, 2007a, p. 366).

Pese a que esta propuesta aún no ha sido sometida a crítica, es imaginable que le será dirigida la misma crítica formulada en contra de la consideración de supuestos cursos causales hipotéticos ${ }^{30}$. Otra objeción que podría ser formulada, sería la búsqueda de una solución sin recurrir primariamente al carácter profesional de la conducta, o sin comenzar el análisis desde dicha característica (Kudlich, 2004, p. 92). Sin embargo, dicha característica es -correctamente visto- una fortaleza de esta propuesta, en relación a aquellos que se sitúan en contra de un tratamiento privilegiado para las acciones profesionales. Finalmente, podría ser criticable la distinción que formula esta propuesta entre la fase previa y la fase ejecutiva del delito, dado que dicha distinción no se funda en el tenor literal de la disposición legal. Sin embargo, la

\footnotetext{
${ }^{29}$ Dicho conocimiento se presentaría al contrario en un caso en que el comprador del objeto se encuentre en una pelea en la cual requiera inhabilitar a su contendor y el vendedor le entrega sencillamente un objeto idóneo para ello.

${ }^{30}$ La posibilidad de utilizar causas de reserva o cursos causales hipotéticos es revisado y descartado en el apartado 1.1.4.2.
} 
consideración temporal es imprescindible para fundar el carácter colaborativo de un comportamiento en relación con otro.

\subsection{Modelo objetivo-subjetivo. La teoría dominante y el criterio de la ju- risprudencia}

Una teoría mixta (objetiva-subjetiva), se caracteriza por el recurso conjunto a ambos puntos de vista para delimitar a las acciones de apoyo punibles de aquellas impunes. Sin embargo, no resulta completamente claro en cuál orden es aplicado cada elemento, ni cuál filtro tiene más peso en el análisis -se debe concordar con Robles Planas (2003, p. 57 y ss.) cuando sostiene que la teoría aquí expuesta debe ser clasificada simplemente como una teoría subjetiva; así también Kindhäuser (2007a, p. 358). Pese a que aquí se sigue la clasificación propuesta por Roxin-. Algunas veces es aplicado primero el criterio subjetivo (v. gr. el conocimiento sobre la realización delictiva posterior), en otras es utilizado un criterio no suficientemente definido en cuanto a su naturaleza objetiva o subjetiva, como lo es la "disposición reconocible a realizar el hecho". Una parte de la literatura y la jurisprudencia reciente adhiere a este criterio, por lo que se ha convertido en la postura dominante en Alemania.

\subsubsection{Relación de sentido delictivo ${ }^{31}$ y disposición reconocible a realizar el he- cho}

La parte subjetiva de la teoría es explicada por Roxin (2003, p. 214 y ss.) y Schünemann (2007, § 27, Nm. 17y ss.) por medio del siguiente criterio: Der Beitragende kennt den Deliktentschluss des Täters oder rechnet lediglich mit einem deliktischen Verhalten des Täters ${ }^{32}$. Solo en el segundo caso el colaborador puede apelar al principio de confianza, ya que toda persona puede confiar por regla general en que no serán cometidas conductas típicas de forma dolosa. Sin embargo, dicha confianza no puede ser sin más apelada cuando el contribuidor se ha empeñado en apoyar a un autor reconociblemente dispuesto a realizar el hecho (previamente en Roxin, 1989, p. 177 y ss.; $1993, \S 27$, N. 21).

La parte objetiva de la teoría, referida a una determinada cualidad de la acción, entregaría un criterio limitativo para el tipo objetivo. Si bien existen un gran número de opiniones con un fundamento similar, Roxin reclama la autoría del criterio bajo el nombre de la "relación de sentido delictivo" -Kindhäuser (2007a, p. 358) califica a este criterio como una paráfrasis sin contenido, dado que ella no tiene un significado distinto a que una acción de complicidad debe ser una colaboración para un hecho típico y antijurídico-, el cual lo explica por medio de una casuística, afir-

\footnotetext{
${ }^{31}$ Para diferenciar a esta postura respecto de aquella que sostiene que la relación de sentido delictivo solo tiene una naturaleza objetiva, en los términos propuestos por Frisch, ver supra 1.1.3.

32 "El colaborador conoce la decisión delictiva del autor o solo cuenta con un comportamiento delictivo del autor".
} 
mando que el límite de la punibilidad radica en la falta del sentido delictivo del acto. Una relación de sentido delictivo faltaría:

...wenn sich der fördernde Beitrag auf eine legale Handlung bezieht, die schon für sich allein genommen für den Täter sinnvoll und nützlich ist, die dieser aber außerdem zur Voraussetzung für ein davon unabhängiges, auf einem selbstständigen Entschluß beruhendes Deliktsverhalten macht. (Roxin, 2003, p. 208). ${ }^{33}$

Roxin (2003) vincula esta última reflexión con la desarrollada por el BGH bajo el concepto de disposición reconocible al hecho. Sin embargo, no resulta completamente claro si el BGH utiliza dicho concepto en un sentido objetivo o subjetivo ${ }^{34}$, si bien el BGH parece tratar a este criterio desde una perspectiva subjetiva, Greco (2015) sostiene lo contrario. La actualidad y adecuación de la teoría desarrollada por Roxin (2003), es defendida por Schünemann (2007, Nm. 17 y ss.) en la duodécima edición del Leipziger Kommentar.

Otros autores, utilizan formulaciones cercanas. Por ejemplo, de acuerdo con Meyer-Arndt (1989, p. 287), solo pueden venir en consideración a título de complicidad en el sentido del StGB $(1871, \S 27)$ actos de promoción que sean específicos para el hecho delictivo. Por lo mismo, quedarían fuera de dicha categoría los comportamientos neutrales o lícitos. Ransiek (1997, p. 46), por su parte, propone excluir de la punibilidad a título de complicidad a aquellas contribuciones a un hecho que, al mismo tiempo, también sirven a un propósito legal. Wohlers (2000, p. 171 y ss.) describe el desarrollo de un criterio similar por parte del Schweiz BGE, en las sentencias Generaldirektion PTT gegen J. (1985, p. 32); X. gegen Schweizerische Pay-Sat AG, (1988, p. 112). Con posterioridad a una primera fase subjetiva, el Schweiz BGE desarrolló un criterio objetivo en el denominado "caso de la carne de antílope" (B. und S. gegen Staatsanwaltschaft des Kantons Basel-Stadt, 1993, p. 289) bajo la siguiente formulación: ¿queda la prestación desprovista de sentido sin la acción delictiva posterior?. En ese caso la prestación de ayuda prácticamente solo puede ser utilizada de forma ilegal, de modo que la relación de sentido delictiva $-y$ con ello la complicidad punible- debe ser afirmada. Roxin (2003, p. 217) reconoce aquí también, por cierto, la aplicación de su criterio.

Esta teoría enfrenta varias objeciones. Una parte del problema de la teoría radica en su contradictoria construcción y, especialmente, en la identificación del fundamento penal de la complicidad como un ataque independiente del partícipe al bien jurídico. La teoría, pretende pacificar la contradicción existente entre las propuestas objetivas y subjetivas por medio de la apelación a un injusto autónomo y al

\footnotetext{
33 "...si la conducta colaboradora se refiere a una acción legal que para el autor ya en si misma es útil, independiente de que sea además un presupuesto para el comportamiento delictivo basado en una decisión autónoma".

${ }^{34}$ Ver supra 1.3.2.
} 
mismo tiempo accesorio del partícipe, presentando una construcción difícilmente aceptable. El propósito unificador de la teoría sería alcanzado por medio de una determinada comprensión de la teoría de la imputación objetiva, que se encuentra abierta a los conocimientos especiales del autor como límite al requisito general de que la actuación sea constitutiva de la creación o incremento de un riesgo no permitido, radicando el carácter no permitido de la conducta del cómplice en el conocimiento que tiene de los planes del autor (Roxin, 1993b, Nm. 22). Sin embargo, dicha integración no está exenta de dificultades teóricas. ¿Cómo puede ser conciliado este criterio subjetivo (¿prioritario?) con las reglas de la imputación objetiva? Greco (2015, p. 3) -previamente Wohlleben (1996, p. 120 y ss.) tomó el mismo camino- es consciente de este problema de consistencia y lo vincula al tratamiento de los denominados conocimientos especiales dentro de la imputación objetiva, como un intento de búsqueda de una correcta ubicación sistemática para la solución teórica. El traslado del principio de confianza desde la imprudencia al dolo eventual, no convence (Kudlich, 2004, p. 123). Pese a que resulta bastante claro que el principio de confianza constituye un límite a los deberes de cuidado, el traslado del límite se sustenta en una (incorrecta) comprensión de la imprudencia, y el dolo como una estructura de imputación continua diferenciada (cuantitativamente) por el grado de conocimiento o el grado de certeza atribuido al pronóstico lesivo, en las cuales la infracción de deberes de cuidado o la realización de un riesgo no permitido juega un rol constitutivo para ambas. Cuando dicho paralelismo es rechazado, entonces la propuesta teórica se presenta como inadecuada, fundamental a este respecto Kindhäuser (2010, p. 403 y ss.).

Adicionalmente, el alcance y utilidad del criterio es dudoso. Como notó Amelung (1993, p. 13) y concuerdan, Wohlers (2000, p. 172); Beckemper (2001, p. 167); y Otto (1998, p. 207), casi toda prestación que es entregada con anterioridad a la fase ejecutiva puede ser usada por el receptor con distintos fines, sean estos punibles o lícitos, un buen ejemplo en el mismo sentido lo entrega Amelung (1999): Alguien puede considerar su acción con sentido al prestarle un martillo a un amigo, de quien sabe que tiene la intención primero de golpear la cabeza de su señora y luego de clavar un clavo en la pared. ¿Significa esto que una prestación de ayuda puede tener una parte legal y otra ilegal? En Derecho penal la acción puede cargar con una sola cualificación.

\subsubsection{El criterio de la jurisprudencia}

La literatura se refiere en sus contribuciones a diferentes y numerosas sentencias, sin coincidir necesariamente en ellas. Pese a que el criterio actual del BGH tiene una prehistoria -el caso más conocido previo a la elaboración de este criterio es el denominado "caso del burdel" (1906, RGSt 39 44), en el cual el RG (excluyó la posibilidad de sancionar a título de complicidad en el proxenetismo el suministro continuo de pan y carne al dueño del burdel. Aún cuando dicho suministro servía al sustento 
de proxenetas y prostitutas, dicho apoyo no se encontraba en una relación estrecha con el servicio de proxenetismo. Al contrario de esta conclusión, el suministro de vino al mismo dueño del burdel fue sancionado a título de complicidad, dado que las bebidas alcohólicas aumentan la frecuencia y duración de las visitas al burdel, quienes tienen un motivo adicional para visitarlo. ¿Cómo fundamentó el RG el supuesto límite entre ambos suministros? El RG afirmó que el suministro de vino se encuentra en una relación más estrecha con la actividad de proxenetismo del dueño del burdel. Schünemann (2007, Nm. 21) sorprendentemente concuerda con este resultado. Crítico con este resultado, al contrario, Roxin (1993b, Nm. 20) y Puppe (1998, p. 27)- , en este apartado solo se expondrá el criterio objetivo-subjetivo desarrollado por dicho tribunal supremo por medio de algunas sentencias. En las contribuciones de MeyerArndt (1989, p. 282 y ss.) y Lesch (2014, p. 453 y ss.) se encuentra una detallada exposición de las sentencias.

El denominado "caso de la evasión de impuestos" (5 StR 624/99, 2000) resume una serie de tres sentencias del 5. Senado del BGH de los años 1998 (5 StR 746/97), 1999 (5 StR 729/98) y 2000 (5 StR 624/99). En dicha decisión, el BGH aplicó el criterio ya desarrollado previamente en el denominado "caso del folleto comercial" (5 StR 729/98,1999), para el arduamente discutido problema de la colaboración de los empleados bancarios en una evasión tributaria, declarando que dichos principios tienen validez general (Roxin, 2003, p. 217). La distinción más relevante del criterio radica en el conocimiento de quien colabora:

Zielt das Handeln des Haupttäters ausschließlich darauf ab, eine strafbare Handlung zu begehen, und weiß dies der Hilfeleistende, so ist sein Tatbeitrag als Beihilfehandlung zu werten [...] Weiß der Hilfeleistende dagegen nicht, wie der von ihm geleistete Beitrag vom Haupttäter verwendet wird, hält er es lediglich für möglich, daß sein Tun zur Begehung einer Straftat genutzt wird, so ist sein Handeln regelmäßig noch nicht als strafbare Beihilfehandlung zu beurteilen, es sei denn, das von ihm erkannte Risiko strafbaren Verhaltens des von ihm Unterstützten war derart hoch, daß er sich mit seiner Hilfeleistung "die Förderung eines erkennbar tatgeneigten Täters angelegen sein" ließ...(5 StR 624/99, 2000, B, I, 2, c) ${ }^{35}$

Otto (2001) discute ese resultado, dado que no existiría seguridad en la comisión de una evasión de impuestos posterior, desde que no toda transferencia anónima es seguida de una evasión de impuestos. En este sentido sostiene que "Bei Sparkassen, Volksbanken und anderen kleinen Banken erscheint es angemessen, davon

\footnotetext{
35 "Si la acción del autor principal se dirige exclusivamente a cometer una acción delictiva, y ello es conocido por el colaborador, entonces su acción colaborativa debe ser evaluada como acción de complicidad [...] Si el colaborador al contrario no conoce cómo será utilizada su contribución ya prestada al autor, pero cree solamente como posible que su actuar será usada para cometer un hecho delictivo, entonces su acción no debe ser evaluada en términos generales como una acción de complicidad punible, a menos que el riesgo reconocible de un comportamiento punible para el colaborador sea tan alto que él con su prestación de ayuda se ha empeñado en apoyar a un autor reconociblemente dispuesto a realizar el hecho".
} 
auszugehen, dass weniger als 70\% der anonymen Überweisungen mit einer Steuerhinterziehung verbunden waren" (p. 443) ${ }^{36}$.

El elemento más importante se encuentra vinculado al dolo: el colaborador sabe o simplemente cree como posible que su hacer será utilizado para cometer un hecho punible. Una restricción de la imputación, de acuerdo con la opinión del BGH, solo podría venir en consideración por definición para el dolo eventual (Lesch, 2014, p. 458), Greco (2015), resume el criterio bajo la siguiente fórmula: "Der Gehilfe, der um die Haupttat sicher weiß, macht sich strafbar; der zweifelnde ,Gehilfe' bleibt grundsätzlich straflos, es sei denn, er fördert einen erkennbar Tatgeneigten" (p. 1) ${ }^{37}$. Según Roxin (2003, p. 218), el citado criterio del BGH contiene también como elemento objetivo la relación de sentido delictivo. Si bien dicho elemento objetivo no estaría explícito en la citada sentencia, ello se encontraría implícito en la oración condicional previamente citada: "Zielt das Handeln des Haupttäters ausschließlich darauf ab, eine strafbare Handlung zu begehen..." (5 StR 624/99, 2000, B, I, 2, c) ${ }^{38}$. Al mismo tiempo, el BGH ha delimitado los bordes de su criterio: no es posible sostener una impunidad general para acciones profesionales o cotidianas. Normalmente la punibilidad de una acción depende del contexto y, por ello, no puede ser descartada la punibilidad anticipadamente. Este principio se encuentra claramente expresado por el BGH en su razonamiento:

Eine generelle Straflosigkeit von "neutralen" , „berufstypischen“ oder „professionell adäquaten" Handlungen kommt dagegen nicht in Betracht. Weder Alltagshandlungen noch berufstypische Handlungen sind in jedem Fall neutral. Fast jede Handlung kann in einen strafbaren Kontext gestellt werden (vgl. Roxin, Festschrift für Koichi Miyazawa 1995 S. 501, 515). Die genannten Begriffe sind daher für sich allein nicht geeignet, strafbare Beihilfe von erlaubtem Handeln eindeutig abzugrenzen. (5 StR $624 / 99,2000, B, 1,2$, c) ${ }^{39}$

Luego de numeras reiteraciones y confirmaciones literales del criterio previamente desarrollado por el BGH (ver Greco, 2015, p. 1, Nota al pie 8) en el denominado "caso del concurso" (5 StR 468/12, 2014), el referido tribunal incorporó explícitamente como criterio objetivo en el acto de colaboración la relación de sentido delictivo (Joecks, 2017, Nm. 63 y 64). El nuevo ingrediente de la teoría ya clásica afirma que:

\footnotetext{
36 "Parece adecuado suponer que menos del 70\% de las transferencias anónimas realizadas en cajas de ahorro y otros pequeños bancos están vinculadas con evasión de impuestos".

37 "El cómplice que conoce con seguridad el hecho principal se hace responsable penalmente; el cómplice dudoso se mantiene fundamentalmente impune a menos que el apoye a un autor reconociblemente dispuesto a realizar el hecho".

38 "si la acción del autor principal se dirige exclusivamente a cometer una acción delictiva".

39 "Una impunidad general de acciones neutrales, habituales en la profesión o profesionalmente adecuadas no viene en consideración. Tanto las acciones cotidianas como las habituales en el ámbito profesional no son en caso alguno neutrales. Casi toda acción puede ser puesta en un contexto punible. Los citados conceptos no son por ello idóneos para distinguir con claridad entre acciones permitidas y aquellas que constituyen complicidad punible".
} 
Aus objektiven Gründen kann eine strafbare Beihilfe zu verneinen sein, wenn dem Handeln des - um die bevorstehende Deliktsverwirklichung wissenden - Täters der "deliktische Sinnbezug" (Schünemann aaO Rn. 18) fehlt, weil das vom Gehilfen geförderte Tun des Haupttäters nicht allein auf die Begehung einer strafbaren Handlung abzielt und der Beitrag des Gehilfen auch ohne das strafbare Handeln des Täters für diesen sinnvoll bleibt (vgl. Schünemann aaO). (5 StR 468/12, 2014, Rn. 28) ${ }^{40}$

La decisión del $\mathrm{BGH}$, trajo consigo también una precisión sobre el aspecto subjetivo de la teoría. Para ello, se apela nuevamente al principio de confianza, excluyendo la posibilidad de sancionar penalmente a la simple sospecha de uso delictual de las acciones cotidianas o socialmente no indeseadas. El criterio desarrollado por el BGH en dicho sentido, afirma textualmente que:

Subjektiv besteht insoweit Anlass zu einer Begrenzung der Beihilfestrafbarkeit, als der Außenstehende eine deliktische Verwendung seines Beitrags durch den Täter zwar für möglich hält - also mit dolus eventualis handelt - aufgrund des Alltagscharakters seines Tuns aber darauf vertrauen darf, dass der andere dieses nicht zur Begehung einer vorsätzlichen Straftat ausnutzen wird (vgl. Schünemann aaO Rn. 19; näher zum Vertrauensgrundsatz Roxin, FS Tröndle, 1989, S. 177). Indem der Bundesgerichtshof in den Fällen, in denen der Hilfeleistende nicht weiß, wie der von ihm geleistete Beitrag vom Haupttäter verwendet wird, die Strafbarkeit davon abhängig macht, ob das vom Hilfeleistenden erkannte Risiko strafbaren Verhaltens des von ihm Unterstützten derart hoch ist, dass er sich mit seiner Hilfeleistung die Förderung eines erkennbar tatgeneigten Täters angelegen sein lässt, wird sichergestellt, dass sich niemand durch bloße Mutmaßungen über die Möglichkeit einer strafbaren Verwendung von alltäglichen, sozial nicht unerwünschten Handlungen abhalten lassen muss. (5 StR 468/12, 2014, Rn. 29) ${ }^{41}$

El BGH renuncia citar a Amelung (1999, p. 26), quien formuló y desarrolló este criterio, distinguiendo entre la asunción de un riesgo de resultado concreto y la asunción de un riesgo abstracto del asunto ${ }^{42}$.

\footnotetext{
40 "Una complicidad punible puede ser negada desde fundamentos objetivos cuando falta la relación de sentido delictivo de la acción del autor (que previamente sabía de la comisión del delito), dado que la acción colaborativa del cómplice no solo se encuentra dirigida a la comisión de una acción delictiva por parte del autor, sino que también conserva su sentido con prescindencia de ella".

${ }_{41}$ "Desde un punto de vista subjetivo se mantiene un motivo para delimitar la punibilidad del cómplice como una persona ajena al empleo delictivo de su contribución por parte del autor, pese a que él la considere como posible (con dolo eventual), pero debido al carácter cotidiano de su acción, puede confiar en que su prestación no será usada por otro para cometer un hecho punible doloso. En aquellos casos en que el colaborador no sabe cómo será utilizado el aporte por el autor, el Tribunal Supremo Alemán hace depender la punibilidad de si el riesgo reconocible de un comportamiento punible para quien colabora es tan alto, que se pueda acreditar que él con su contribución se ha esforzado en colaborar con un autor reconociblemente dispuesto, de este modo, se asegura que nadie deba abstenerse de actuar debido a meras suposiciones sobre la posibilidad de un empleo punible de acciones cotidianas y socialmente no indeseadas".

${ }^{42}$ Ver también infra 1.4.1.
} 
Dado que la función de la judicatura no es la de resolver una disputa dogmática refiriéndose a todo el ámbito de las propuestas teóricas que se han pronunciado sobre ella, no puede ser objeto de crítica el hecho de que en las referidas sentencias se realice una revisión insatisfactoria de todas las propuestas. Al contrario, resulta criticable que el $\mathrm{BGH}$ realice una referencia superficial a los criterios más reconocidos en la materia sin hacer una real reflexión en relación con la aplicabilidad de ellos a su línea argumental, asumiendo que simplemente puede ir sumando criterios diversos sin la necesaria implicación de ellos a su construcción teórica. Por ejemplo, cuando se afirma que una complicidad punible excluye a una acción adecuada socialmente o neutral, sin siquiera referirse a lo qué se entiende bajo dichas categorías teóricas ( 5 StR 624/99, 2000; Kudlich, 2004, p. 135). En relación con el contenido contradictorio del criterio, son aplicables las mismas críticas que fueron formuladas en contra de la teoría de Roxin ${ }^{43}$. Especial preocupación merece la posición sistemática que le es atribuida a la disposición reconocible al hecho en el denominado "caso del concurso" (5 StR 468/12, 2014), en donde se reconoce una tensión interna debido a la mezcla de un punto de vista objetivo dentro del tipo subjetivo. El concepto (objetivo) de disposición reconocible al hecho aparece como límite del principio de confianza, el cual -a su vez- se deja describir como límite de las acciones impunes que son cometidas con dolo eventual (Greco, 2015, p. 2). Es decir, se sigue sosteniendo la pertinencia del principio de confianza más allá de la restricción de los deberes de cuidado propios de la imprudencia, llevándolo (impropiamente) al ámbito del dolo eventual.

\subsection{Restricciones del tipo subjetivo}

Quienes favorecen una solución restrictiva de la punibilidad para estas acciones en el nivel del tipo subjetivo, critican a su vez a las propuestas precedentes que restringen el tipo objetivo del cómplice, dado que ellas pueden llevar consigo una consecuencia indeseada: excluir del ámbito de la punibilidad de la complicidad a las colaboraciones conscientes para la comisión de delitos mediante actos profesionales (Amelung, 1999, p. 17). Es decir, un filtro a nivel de tipicidad objetiva impide que siquiera se analice este tipo de colaboraciones conscientes, lo que resultaría injustificado. Ello explicaría, por qué se hacía - en una primera fase de la jurisprudenciauna diferenciación entre dolo eventual y dolo directo. Sin embargo, ese dolo directo no se refería al conocimiento de quien realiza la acción, sino que a un elemento subjetivo del tipo referido a la supuesta voluntad orientada hacia fines legales o a la ausencia de la así denominada voluntad de colaboración. Un buen ejemplo en dicho sentido, se encuentra en RGSt 37, 321 y OLG Düsseldorf ${ }^{44}$ del 6 de septiembre de 1983 (citado en Hruschka, 1984, p. 261). En el primer caso la acción se encuentra, de acuerdo a la argumentación del RG, es decir "en el cumplimiento de un deber profesional del abogado" (Kudlich, 2004, p. 139 y ss.).

\footnotetext{
${ }^{43}$ Véase supra 1.3.1.

${ }^{44}$ Oberlandesgericht Düsseldorf = Tribunal Regional Superior de Düsseldorf
} 
Las propuestas expuestas en el presente apartado tienen en común un marcado acento en criterios restrictivos de carácter subjetivos, pese a que excepcionalmente- pueden reconocer una restricción del tipo objetivo -pese a que Kudlich (2004, p. 448 y ss.) sigue el criterio de Otto (1998), él propone restricciones objetivas marginales como los serían "la vinculación arbitraria con el hecho posterior" y "la competencia especial"-, por ejemplo, Otto (1998) y Amelung (1999) afirman que las necesidades básicas de carácter existencial deben ser excluidas del concepto de colaboración, Kindhäuser (2007a) concuerda con ese resultado y argumenta convincentemente con el siguiente ejemplo: "So käme niemand auf den Gedanken, dass der Bäcker B dem Habilitanden $\mathrm{H}$ bei seiner wissenschaftlichen Karriere durch den regelmäßigen Verkauf von Brot und Brötchen Hilfe geleistet habe" (p. 366) ${ }^{45}$. Pese a que ambos concuerdan en el resultado, ello responde a diversos fundamentos. Amelung (1999, p. 21) sostiene que el elemento objetivo del tipo colaboración puede ser restringido solo excepcionalmente, dado que la existencia humana es un requisito del comportamiento humano, y dicha existencia no puede ser legal o ilegal. Otto (1998, p. 217 y ss.), por su parte, refuerza dicha exclusión al afirmar que la ley no exige aislar socialmente al delincuente, sino que prohíbe la realización de actos de colaboración para realizar un delito. Es por ello que otro tipo de acciones humanitarias deben ser tratadas bajo el mismo fundamento y ser excluidas del comportamiento penalmente relevante, concuerda con ello también, excluyéndolo del ámbito de lo punible Joekcks (2017. § 27, N. 90 y ss.).

\subsubsection{El concreto punto de vista como comprensión correcta del dolo eventual}

Amelung (1999) favorece básicamente un tratamiento del problema en el tipo subjetivo, el cual se encuentra gobernado por el concepto de "concreto punto de vista" del dolo, como criterio delimitador entre los actos de colaboración que merecen sanción penal y aquellos que no la merecen. Kudlich (2008, p. 229; 2004, p. 338), concuerda con un correctivo de imputación subjetivo semejante. Consecuentemente, solo el concreto punto de vista del colaborador puede ser suficiente para fundar la punibilidad de su acto (Amelung, 1999, p. 25). La asunción de un riesgo comercial abstracto puede ser permitido o no permitido, y su evaluación depende de si la regulación de dicha colaboración lo caracteriza como permitido o no permitido. Un ejemplo concreto de este tratamiento se encuentra en el Waffengesetz (WaffG, 2002, $\S 53)^{46}$, el cual declara como punible el suministro de armas (Amelung, 1999, p. 27). En oposición a la teoría de Roxin, Amelung (1999) afirma que un comportamiento con dolo eventual fundado en el concreto punto de vista del colaborador puede ser punible a título de complicidad, siendo impertinente por ello apelar aquí al principio de confianza.

\footnotetext{
45 "A nadie le vendría la idea de que el panadero $\mathrm{B}$ ha colaborado con el habilitante $\mathrm{H}$ en su carrera científica mediante la venta regular de pan".

${ }^{46}$ Ley de Armas
} 


\subsubsection{Una restricción interpretativa del dolo relevante para la complicidad a través de actividades profesionales}

En oposición a Hassemer, quien propone analizar a las reglas profesionales en el ámbito del tipo objetivo ${ }^{47}$, otros autores aceptan la relevancia de estas reglas para el análisis del comportamiento del cómplice, pero sin reconocer en ellas una restricción absoluta de la punibilidad de la conducta, propia de quienes sostienen su relevancia en dicha sede. Se postula que el Derecho penal debe integrar dichas normas en su análisis, pero en el ámbito del dolo (en este sentido; Kudlich, 2008, p. 227y ss.). En dicho sentido, Otto (2001, p. 443) reconoce al ámbito de los comportamientos profesionales como un campo riesgoso para la punibilidad, dado que esa conducta, a través del comportamiento de una contraparte comercial, podría contener en si misma un carácter criminal. Es ese riesgo de punibilidad, debido al interés de la libertad de trabajo garantizado constitucionalmente (Grundgesetz für die Bundesrepublik Deutschland $^{48}$, GG 1949, art. 12, Nm. 1) y al derecho del consumidor a obtener la prestación, el que debe ser restringido ponderadamente. De acuerdo a la opinión de Otto (2001), si bien dicha restricción se realiza normalmente bajo las categorías habituales del tipo subjetivo, el legislador puede regular dicho riesgo de punibilidad a través de deberes de cuidado y prohibiciones, alterando las reglas generales, Otto (2001, p. 444) nombra la situación del vendedor de armas, el farmacéutico y el empleado del banco cuando ejercer su profesión u oficio-. (Kudlich (2004, p. 222 y ss.). Aquí radica precisamente la importancia de la regulación legal e interna en el ámbito profesional, limitando la libertad en el ejercicio de la profesión. Dentro del riesgo tolerado normativamente, solo se puede fundar la punibilidad de un comportamiento a título de complicidad, si él se encuentra gobernado por medio del conocimiento cierto del comportamiento delictivo posterior. Si el legislador, al contrario, reconoce el riesgo de que un determinado comportamiento profesional o comercial pueda ser aprovechado por un tercero para la comisión de un hecho delictivo y no lo regula, entonces tolera dicho peligro. Sin embargo, esa tolerancia solo alcanza al ámbito del dolo eventual. Es decir, el legislador puede extender la punibilidad en este ámbito más allá del dolo directo, alcanzando también a la colaboración con dolo eventual, en la medida que regule expresamente dichas conductas potencialmente colaborativas de delitos por ser especialmente riesgosas.

Una restricción de este tipo, se funda también por la especial característica normativa que revisten las acciones profesionales: los profesionales no tienen el derecho a negar una prestación en razón de meras sospechas. Sin embargo, si se sale del ámbito de los comportamientos profesionales, el tratamiento debiese cambiar. En el caso de las acciones cotidianas, como lo constituye, por ejemplo, el préstamo de un cuchillo, donde el prestador reconoce (con dolo eventual) el riesgo concreto

\footnotetext{
${ }^{47}$ Ver supra 1.1.2.

${ }^{48}$ Constitución de la República Federal de Alemania.
} 
de una acción punible, dicho prestador se encuentra autorizado por el derecho a omitir una acción que desde su perspectiva podría fomentar la realización de un delito (Otto, 2004, p. 336), Kudlich (2004, p. 424 y ss.), concuerda con esta argumentación y agrega que la habitualidad y motivación del suministro de un bien o servicio son distintos por parte de privados y profesionales). Según Otto (2001, p. 440), no existe una restricción general del tipo objetivo en este ámbito, dado que el legislador no ha decidido, a través de acción u omisión, en dicho sentido. Es por ello, que el grado de conocimiento constituye el criterio prioritario de la construcción teórica para distinguir entre contribuciones punibles e impunes. De esta forma, Otto (2001, p. 441) considera correcto el punto de partida del criterio diferenciador del $\mathrm{BGH}$, dado que el aspecto externo de un comportamiento puede no revelar suficiente información para realizar su evaluación jurídica, "Erst seine Ziel- und Zwecksetzung verleiht ihm den sozialen Sinngehalt" (Otto, 2004, p. 336) ${ }^{49}$. Es por ello que se debe diferenciar entre conocimiento cierto y mero reconocimiento de una posibilidad, tal como lo ha sostenido la jurisprudencia del BGH. Una colaboración con conocimiento cierto es siempre punible, y solo cuando la utilización delictiva del aporte no es conocido con dolo directo procede el segundo criterio, esto es, la distinción entre acciones cotidianas y profesionales.

Esta vía de solución subjetiva, recibe comúnmente dos objeciones de relevancia. Por una parte, se sostiene que las opiniones teóricas que sostienen una división de acuerdo al grado de dolo se encuentran en las cercanías de un "Derecho penal del ánimo" (Hassemer, 1995a, p. 43); Frisch (1988) califica a ese límite como "Derecho penal del ánimo en la cultura jurídica" (p. 298), por medio de una delimitación que, adicionalmente, es dogmáticamente poco prolija. Las teorías objetivas critican que la delimitación del carácter punible de un comportamiento sea realizada por medio del conocimiento del colaborador, dado que el objeto de prohibición debe ser siempre determinado a través de criterios objetivos (Kindhäuser, 2007a, p. 360). El tratamiento de un problema dogmático por medio de instrumental subjetivo prueba normalmente la incapacidad de la teoría para resolverlo o, simplemente, la incomprensión del problema. Si lo que se quiere prohibir es un determinado comportamiento, no se debe prohibir la intención que lo gobierna, sino que el comportamiento realizado de forma consciente, evitando con ello la objeción referida a un Derecho penal del ánimo. Amelung (1999, p. 25) refuta dicha crítica, afirmando que quien participa conscientemente en un hecho delictivo no solo manifiesta un ánimo contrario al Derecho, sino que también contribuye a ocasionar una lesión al bien jurídico protegido. Por otra parte, se le formula como crítica adicional a esta solución, que la restricción del dolo del partícipe no es conciliable con el tenor literal del § 27 StGB (Kindhäuser, 2007a, p. 359). Pese a que Amelung (1999, p. 26) en principio acepta la objeción, la considera de poca relevancia dado que el fin de la prohibición de complicidad puede modelar el alcance del dolo del cómplice.

\footnotetext{
49 “La determinación de su fin y objetivo le entrega primero su contenido de sentido social”.
} 


\subsection{Restricción de la punibilidad a través del reconocimiento de una cau- sa de justificación}

Algunos autores, proponen el tratamiento de situaciones profesionales excepcionalmente en el nivel de la antijuridicidad. El caso de mayor relevancia a este respecto se encuentra en el derecho al asesoramiento jurídico. ¿Merece el asesoramiento jurídico un tratamiento especial? Amelung (1999, p. 27 y ss.) asiente y agrega el fundamento: una argumentación con causas de justificación limitadas tendría la ventaja de llevar el tratamiento del problema a un esquema de reglas, excepciones y contra excepciones (en contra de un reconocimiento general de una causa de justificación, está Hruschka, 1984, p. 257 y ss.). Así podría ser tratado adecuadamente, por ejemplo, el caso de abuso del derecho por parte del abogado defensor. Otto (2001) se declara en contra de esta postura utilizando para ello el ejemplo de un abogado defensor que utiliza judicialmente un documento respecto del que duda sobre su veracidad. En aplicación de su teoría, Otto $(2001, \text { p. 438 })^{50}$ afirma que el uso consciente de un medio de prueba falso sería antijurídico, dado el derecho a defensa encontraría su límite en la prohibición de poner en peligro la administración de justicia. Así, la punibilidad del defensor requeriría aquí dolo directo, pese a que -para la generalidad- el uso de documentos falsos es punible también con dolo eventual.

Precisamente porque el ejercicio de un derecho puede ser visto siempre como una causa de justificación, es que el nivel de la antijuridicidad constituye el lugar potencialmente adecuado para encontrar una solución para el caso previamente referido del abogado defensor, a menos que una interpretación restrictiva del tipo lo permita -evidentemente esta propuesta encuentra un lugar fecundo en el Código Penal (1874, art. 10, no. 10)-. El problema de dicho acercamiento radica en la incapacidad del criterio para ser generalizado, de modo que dicho modelo solo puede funcionar en casos de verdaderas colisiones de derechos. Las así denominadas acciones neutrales, no reclaman para sí un derecho cuando se basan en la adecuación social o habitualidad del comportamiento. Es siempre importante resaltar, que la ponderación entre utilidad de una actividad y su prohibición para proteger bienes jurídicos es tarea del legislador.

\section{Valoración de las propuestas de solución y la necesidad de un cambio en el punto de partida en el análisis}

Dado que se ha elegido en el apartado anterior exponer a las propuestas teóricas junto con sus objeciones, en este apartado se opta por evitar una nueva evaluación de cada propuesta de tratamiento de las acciones neutrales, centrando el análi-

\footnotetext{
${ }^{50}$ Ver 1.4.2
} 
sis en la necesidad de cambiar la perspectiva para abordar la discusión y el rendimiento teórico que ello puede conllevar.

\subsection{La identificación de los distintos niveles de la discusión}

La primera tarea a la que nos vemos enfrentado, es la ordenación del estado de la discusión y sus implicaciones. La discusión tiene distintos niveles, y se vincula con distintos requisitos teóricos. Por una parte se encuentran quienes, desde un punto de vista propio de la política criminal, abogan a favor -típicamente debido a la utilidad de la actividad, el derecho fundamental de la GG (1949, art. 12) y la inadecuación de una prohibición general de una actividad lícita- (Kudlich, 2004, p. 289 y ss. $)^{51}$, o en contra de una restricción de la punibilidad en este ámbito basada en un privilegio profesional (ver solamente Beckemper, 2001, p. 169). Por otra parte, se encuentran los argumentos a favor y en contra de determinadas propuestas restrictivas, como disputa dogmática con pretensiones de verosimilitud sobre el Derecho vigente. Dichas teorías, comienzan su argumentación (en mayor o menor medida) con la constatación de que no habría una verdadera restricción legal para la exclusión de las acciones neutrales del ámbito de lo punible a título de complicidad. Así, de acuerdo con este punto de partida, cada contribución causal —en el sentido de la conditio sine qua non - puede ser visto como una contribución punible para el resultado delictivo, ya sea a título de autoría o de complicidad. Así, sería la función de una teoría de la imputación objetiva o de la categoría de la imputación subjetiva, situar los filtros adecuados para evitar sancionar dichas conductas. El problema, es que aquellas implicaciones usualmente no escritas pueden ser erróneas, y cuando los presupuestos no son los correctos, las conclusiones que se siguen de ellos suelen ser asimismo incorrectas o devenir las correcciones postuladas simplemente en innecesarias. Para asumir la necesidad de excluir de la punibilidad a las denominadas acciones neutrales o profesionales en niveles posteriores del análisis de la teoría del delito, primero debe aceptarse dicho punto de partida: que aquellas conductas satisfacen el supuesto de hecho previsto en la regla de comportamiento que extiende la punibilidad al cómplice, en tanto dicha norma establecería como requisito la necesidad de que la conducta del cómplice sea una condición necesaria para el resultado, respondiendo así a un paradigma causalista de la participación.

Sin considerar los distintos niveles de la discusión, las teorías se presentan como una disputa lingüística sobre determinadas formas jurídicas a las que se puede recurrir indistintamente para solucionar el problema. Sin embargo, la diferencia entre las teorías no se basa solamente en sus criterios restrictivos (superficiales) y conclusiones para un determinado grupo de casos (por ejemplo, sobre la adecuación social o profesional de un comportamiento, la relación de sentido delictivo, el carácter esencial o no de una contribución, la reconocible disposición al hecho del autor, etc.),

\footnotetext{
${ }^{51}$ Especialmente p. 292 y ss.
} 
sino que también tanto en relación a sus presupuestos e implicancias como su grado de vinculación con el Derecho vigente y su integración con el sistema jurídico penal en su conjunto. En la medida que las propuestas teóricas, son planteadas como aplicaciones pretendidamente idóneas de dichas teorías para resolver un problema concreto de interpretación y/o aplicación del Derecho vigente. Así, resulta imprescindible atender a todos los niveles de la discusión para alcanzar la correcta perspectiva para evaluar a las diversas teorías dogmáticas que pretenden dar una respuesta racional a este problema. Sobre las pretensiones de racionalidad del discurso dogmático y la forma de evaluar disputas dogmáticas, ver Schurmann Opazo (2019, p. 567 y ss).

De esta forma, las dificultades que se presentan para el tratamiento dogmático de este tipo de comportamientos no radican en el carácter no sospechoso de la conducta, sino que se basan principalmente en falta de procesamiento del problema mediante las categorías dogmáticas correctas, esto es, el reconocimiento de la relevancia de los requisitos legales de la complicidad y (mediatamente) del fundamento de la punibilidad del partícipe. Ante la supuesta ausencia de criterios restrictivos en el tenor literal de la regulación legal de la complicidad, la discusión ha avanzado de la mano de criterios generales de la responsabilidad penal, perdiendo de vista la especificidad de la extensión de la punibilidad al partícipe por la realización de un hecho punible de otro. El fundamento penal de la complicidad suele transitar entre dos consideraciones: el principio de responsabilidad por el hecho propio o de auto responsabilidad y el carácter accesorio de la complicidad, la que se encuentra en una determinada relación con el injusto del autor principal. Ambos elementos son necesarios -una completa exposición del problema se encuentra en Roxin (1993a, p. 365 y ss.). Para una exposición resumida ver Kindhäuser (2015b, p. 332)- para fundar la punibilidad del partícipe, sin embargo, la correcta articulación de dichos principios permite comprender cómo debe ser analizado el comportamiento del cómplice por las categorías tradicionales de la teoría del delito. Así, primero se debe determinar, por ejemplo, si el comportamiento del cómplice debe ser causal para el resultado delictivo, para luego discutir la pertinencia de la teoría de la imputación objetiva (al menos en su dimensión como selector de cursos causales penalmente relevantes) para la teoría de la autoría y participación ${ }^{52}$. El carácter accesorio de la complicidad, por su parte, permite esbozar la primera conclusión: una consideración exclusivamente aislada de la acción de complicidad, no permite formular una adecuada distinción entre colaboraciones punibles de las impunes. Como acertadamente destacó Amelung (1999, p. 17; De acuerdo también Kindhäuser, 2015b, p. 383), toda presta-

\footnotetext{
${ }^{52}$ En virtud de ello, la teoría dominante sostiene que la conducta del cómplice no solo debe constituir una causa necesaria del resultado dañoso -de acuerdo con la teoría de la equivalencia de las condiciones- sino que también debe constituir la creación o el incremento de un riesgo no permitido, en donde el límite al riesgo permitido viene dado por el conocimiento que tiene el colaborador sobre la decisión delictiva del autor. Y dicho conocimiento o pronóstico, por regla general, debe satisfacer un estándar más exigente que el habitual, el dolo directo. Ver supra 1.3.1.
} 
ción de ayuda ejecutada en la etapa de actos preparatorios de un delito puede ser utilizada por el receptor para distintos fines. Es precisamente por ello que la "neutralidad" de una acción es un problema de su descripción ${ }^{53}$, y la descripción de dichos hechos deben ser analizados a partir de las categorías penales correctas.

\subsection{La razón del insatisfactorio estado de la discusión: La sustitución de las restricciones previstas en el tenor literal de la regla que sanciona la complicidad a través de la adición de criterios restrictivos externos}

Tal como se ha señalado reiteradamente, la opinión dominante en Alemania ha trabajado bajo la asunción de que la regla que sanciona la complicidad no tiene restricción alguna que permita excluir de la punibilidad de las acciones neutrales o cotidianas. Debido a ello, ha desarrollado un criterio (objetivo-subjetivo) externo a la regla legal que sanciona la complicidad para limitar la punibilidad en este ámbito. Pese a la aparente estabilidad de este criterio, este se basa en una construcción teórica sistemáticamente contradictoria y no ofrece claridad en relación a la prioridad del criterio objetivo ("relación de sentido delictivo" o "disposición reconocible al hecho") o del subjetivo (conocimiento o solo aceptación de la posibilidad por parte del partícipe). La simple adición de criterios no entrega una solución pulcra y generalizable para solucionar los casos más complejos, sino que solo la posibilidad de realizar una modificación ex post y ad hoc de elementos de la teoría, cuando el resultado no se corresponde con un determinado sentimiento jurídico de corrección. Sin embargo, este paradigma puede ser reconstruido bajo otra comprensión para fundar una solución coherente y segura.

Una solución al problema susceptible, de ser seguida debe contener tanto una construcción teórica consistente como también proponer soluciones adecuadas y fecundas. De esta forma una teoría dogmática, en tanto discurso reflexivo de aplicación, desempeña su pretensión de racionalidad tanto en su fuerza aclaratoria del alcance de las reglas, como en la ausencia de contradicciones valorativas y sistemáticas entre sus presupuestos y aplicaciones pretendidas. Así, es objeto de evaluación de las teorías la relación entre el centro o fundamentos de ella con sus aplicaciones (Schurmann Opazo, 2019, p. 577 y ss.), en este sentido también Schünemann (2012), quien afirma como tarea de la dogmática que "das daraus entstehende Begriffs- und Argumentationssystem muss widerspruchsfrei sein (,deduktive Logik als Organon der Kritik')" 54 . Concuerda también Kindhäuser (2009, p. 959 y ss.) cuando aplica como medida de corrección de la construcción de una teoría, la correspondencia de la teoría con los criterios de los cánones interpretativos y los paradigmas fundamentales. Por ejemplo, una crítica en dicho sentido es inferida cuando se afirma que la catego-

\footnotetext{
${ }^{53}$ Véase supra 1.3.

54 "los sistemas de conceptos y de argumentación [surgidos de fundamentos racionales] deben estar libres de contradicciones (lógica deductiva como instrumento de la crítica)" traducción libre del original.
} 
ría de los conocimientos especiales del autor intenta determinar qué puede ser visto "objetivamente" como complicidad, en tanto resultado de la teoría de la imputación objetiva (Greco, 2015, p. 2). Sin embargo, es simplemente impensable que de acuerdo a una supuesta teoría "objetiva", se haga depender la satisfacción de la tipicidad objetiva de la conducta del querer o conocer del actuante. El sostener que esta solución es consistente con la categoría de los conocimientos especiales del autor dentro de la teoría de la imputación objetiva, está lejos de resolver el problema sistemático, sino que, en su lugar, solo confirma la inadecuación de la categoría de los conocimientos especiales en general. Para introducirse en la discusión ver Roxin (2006, p. 378 y ss.) y, Roxin (1993b, p. 217 y ss.). Para una convincente crítica de esta construcción ver Kindhäuser (1989, p. 61 y ss., p. 91 y ss.).

Externamente, la corrección de las teorías se mide por su capacidad explicativa y compatibilidad con el Derecho vigente - porque la ley constituye el objeto de la dogmática. Kindhäuser, (2009, p. 959 y ss.)-. Tanto teorías objetivas como subjetivas sufren en general la misma objeción. Ambas no son conciliables fácilmente con el tenor literal de la ley (Kindhäuser, 2007a, p. 359). Otto (2001) critica en el mismo sentido, pero solo en contra de una restricción objetiva, sosteniendo que "Der Gesetzgeber hat sich in Kenntnis des, Sozialadäquanzproblems' gegen eine Tatbestandseinschränkung entschieden und diese Entscheidung auch hinreichend klar zum Ausdruck gebracht" (p. 440) ${ }^{55}$. No existe una restricción del dolo en la ley, así como tampoco una autorización legal para comportamientos cotidianos o profesionales. Los comportamientos profesionales, no se encuentran exentos de la prohibición de colaborar con comportamientos delictivos (Kindhäuser, 2007, p. 371). Es por ello que toda teoría que pretenda establecer un criterio delimitador de las conductas punibles en este ámbito, debe prever que la solución propuesta sea compatible con el tenor literal de la legislación y de las categorías penales. Resulta bastante llamativo notar que la mayoría de las propuestas teóricas aquí expuestas no se basan en el tenor literal de la ley, sino que en el uso de criterios ad hoc (v. gr. relación de sentido delictivo, disposición reconocible al hecho, entre otros) o de categorías con contenido difuso (v. gr. adecuación social, riesgo permitido y prohibición de regreso). Una dogmática penal orientada científicamente debe rechazar este tipo de construcciones dogmáticas artificiales, dado que ellas pueden conducir a resultados inseguros, ilógicos o inadecuados (Kindhäuser, 2009, pp. 954 y 955; Schurmann Opazo, 2019, p. 569 y ss.).

Es también digno de notar que los distintos criterios alcanzan frecuentemente las mismas soluciones. Como prueba de ello, dos ejemplos: (i) Pese a que es discutido aún por Roxin el resultado de impunidad debido a la general disponibilidad de un objeto o prestación, constituye un lugar común al día de hoy entre las distintas teo-

55 "El legislador, en conocimiento del 'problema de la adecuación social' se ha decidido en contra de una restricción del ámbito típico y dicha decisión ha sido puesta de manifiesto de forma suficientemente clara". 
rías $^{56}$. El punto de inflexión en dicho desarrollo lo constituye la aprobación del criterio por parte del discípulo de Roxin, Luis Greco $\left(2015\right.$, p. 4) ${ }^{57}$. (ii) Una fuerte barrera objetiva de la punibilidad de acuerdo a la idea de rol, la cual fue desarrollada primariamente por Jakobs, fue dejada paulatinamente de lado y cambiada, entre otros, por el propio Jakobs. La inadecuación de sus resultados y la progresiva consideración del contexto delictual condujeron a ello. Sin embargo, la similitud en los resultados no puede llevarnos a renunciar a la búsqueda de los fundamentos correctos y seguros que permitan fundar una solución aceptable y generalizable, dado que conclusiones correctas o parcialmente correctas suelen estar basadas en fundamentos incorrectos, este parece ser precisamente el caso.

De esta forma, el fundamento de esta insatisfacción en el estado de la discusión se encuentra mucho más en el inadecuado tratamiento del tenor literal de la ley y de las categorías penales, que en la ausencia de un criterio restrictivo convincente (Beckemper, 2001, p. 163) o en una disparidad inaceptable en los resultados de las propuestas teóricas.

Así las cosas, el punto de inicio de cualquier investigación teórica sobre la punibilidad a título de complicidad de las denominadas acciones neutrales, debe necesariamente ser el tenor literal de la regulación legal que establece la punibilidad a título de complicidad, de modo que la conducta pueda ser subsumida en el supuesto de hecho que es descrito en dicha disposición. Así, una correcta teoría de la complicidad esta llamada a abarcar este supuesto como una de sus aplicaciones teóricas pretendidas, sin mayor especificidad que el de ser comportamientos que habitualmente limitan con la irrelevancia penal. En este sentido, mientras que para nuestro Derecho la pregunta fundamental consistirá en qué se entiende por cooperar a la ejecución del hecho (de una forma distinta al autor), para el Derecho penal alemán la pregunta consiste en qué se entiende por prestar dolosamente ayuda a otro para la comisión dolosa de un hecho antijurídico. De este modo, resultará crucial reconocer en los conceptos de cooperación o prestación de ayuda un contenido que excluya a la mera entrega de un producto fácilmente accesible en el mercado, y así poder excluir la subsunción de la mayor parte de las conductas habituales, neutrales y/o profesionales de la regla legal que extiende la responsabilidad penal a quien colabora con la comisión de un hecho típicamente antijurídico de otro. Solo después de que la tipicidad objetiva del comportamiento ha sido determinada como objeto de la imputación, puede serle atribuido dolo a dicho comportamiento, en tanto criterio de imputación -para la distinción entre objeto y criterio de la imputación, ver Vogel (1993 y p. 37 y ss.); Kindhäuser (1989, p. 29 y ss.)-. Plantear una teoría que delimite el comportamiento punible a título de complicidad, como objeto de la imputación de la responsabilidad por el delito cometido por otro, y determine los criterios de impu-

\footnotetext{
${ }^{56}$ Para la crítica y su respuesta ver supra 1.1.4.2.

${ }^{57}$ Ver supra 1.1.4.2.
} 
tación subjetiva pertinente para dicha estructura de imputación excede a las pretensiones de este trabajo y podrá quedar para otra oportunidad.

\section{Reconocimientos}

El autor agradece la lectura atenta de un primer borrador de este texto -y su colaboración con la edición del mismo- al ayudante ad honorem del Departamento de Ciencias Penales de la Universidad de Chile, don Joaquín Rojas-May.

\section{Referencias Bibliográficas}

Aichele, A. (2011). Ex contradictione quodlibet-die untauglichkeit der äquivalenztheorie zur erklärung von kausalität, die untauglichkeit der lehre von der objektiven zurechnung zur rechtfertigung von zurechnungsurteilen und ein vorschlag zur güte. Zeitschrift für die gesamte strafrechtswissenschaft, 123(2), 260-283, doi: $10.1515 /$ zstw.2011.260

Amelung, K. (1999). Die "Neutralisierung" geschäftsmäßiger Beiträge zu fremden Straftaten im Rahmen des Beihilfetatbestands. En E. Samson, F. Dencker, P. Frisch, H. Frister, and W. Reiß, Festschrift für Gerald Grünwald zum siebzigsten Geburtstag (pp.930). Baden-Baden: Nomos.

Ananías Zaror, I. (2010). Prohibición de regreso. Revista de estudios de la justicia, (13), 229-252. Recuperado de https://bit.ly/3n9hxpu

B. und S. gegen Staatsanwaltschaft des Kantons Basel-Stadt, BGE 119 IV 289 (Schweizerisches Bundesgericht 13. Oktober 1993). Recuperado de https://bit.ly/2RFZxYU

Beckemper, K. (2001). Strafbare beihilfe durch alltägliche geschäftsvorgänge. Jura, (3), 163-169.

Beihilfe zum Betrug, 5 StR 729/98 (Bundesgerichtshof 20. September 1999). Recuperado de https://bit.ly/3oX9YmN

Beihilfe zur Steuerhinterziehung, 5 StR 624/99 (Bundesgerichtshof 1. August 2000). Recuperado de https://bit.ly/33Egwgm

Bloy, R. (1985). Die Beteiligungsform als Zurechnungstypus im Strafrecht. Berlin: Duncker \& Humblot. doi: 10.3790/978-3-428-45743-4

Bordellfall, RGSt 39, 44 (Reichsgericht in Strafsachen 14. Juni 1906)

Brennenstuhl, W. (1975). Handlungstheorie und handlungslogik. Kronberg: Scriptor.

Brennenstuhl, W. (1980). Ziele der handlungslogik. En H. Lenk (Ed.), Handlungstheorien interdisziplinär: handlungslogik, formale und sprachwissenschaftliche handlungsthe- 
El tratamiento de las denominadas acciones neutrales a título de complicidad...

orien (Vol. 1, pp. 35-66). München: Wilhem Fink. Recuperado de https://bit.ly/3v87NyD

Código Penal. Diario Oficial de la República de Chile, Santiago, Chile, 12 de noviembre de 1874. Recuperado de http://bcn.cl/2f6m7

Contesse Singh, J. (2018). Tentativa de delito y concurso de personas en el hecho punible en la obra de Eduardo Novoa Monreal. En K. Ambos y J. L. Guzmán Dalbora (Eds.), Derecho y cambio social. Estudios críticos en homenaje a Eduardo Novoa Monreal (pp. 113-140). Santiago: DER.

Contreras Chaimovich, L. (2018). Reglas extrajurídicas y creaciones de riesgos toleradas o desaprobadas en los delitos culposos de homicidio y lesiones. Política criminal, 13(25), 387-444. doi: 10.4067/S0718-33992018000100387

Duff, R. A. (1990). 'Can I help you?' Accessorial liability and the intention to assist. Legal studies, 10(2), 165-181. doi: 10.1111/j.1748-121X.1990.tb00598.x

Frisch, W. (1988). Tatbestandsmäßiges verhalten und zurechnung des erfolgs. Heidelberg: C. F. Müller.

Frisch, W. (2002). Beihilfe durch neutrale handlungen. En C. Prittwitz, M. Baurmann, K. Günther, L. Kuhlen, R. Merkel, C. Nestler, y L. Schulz (Eds.), Festschrift für Klaus Lüderssen: zum 70. Geburtstag am 2. Mai 2002 (pp. 539-558). Baden-Baden: Nomos.

Garrido Montt, M. (2017). Derecho penal: parte general (Vol. 2). Santiago: Jurídica de Chile.

Generaldirektion PTT gegen J., BGE 111 IV 32 (Schweizerisches Bundesgericht 18. Februar 1985). Recuperado de https://bit.ly/3ujDOD3

Greco, L. (2015). Strafbarkeit der berufsbedingten bzw. neutralen beihilfe erst bei hoher wahrscheinlichkeit der haupttat. Wistra (Heidelberg), (1), 1-6.

Grundgesetz für die Bundesrepublik Deutschland, Bundesgesetzblatt Teil III, Bonn, República Federal Alemana, 23 de mayo de 1949. Recuperado de https://bit.ly/2QlecIT

Guzmán, N. (2010). Conductas neutrales y participación en el delito. SSRN. Recuperado de https://bit.ly/3gvLIpU

Hassemer, W. (1995a). Professionelle Adäquanz. Bankentypisches Verhalten und Beihilfe zur Steuerhinterziehung. Teil 1. Wistra (Heidelberg), (2), 41-46.

Hassemer, W. (1995b). Professionelle Adäquanz. Bankentypisches Verhalten und Beihilfe zur Steuerhinterziehung. Teil 2. Wistra (Heidelberg), (3), 81-87. 
Hruschka, J. (1984). Anmerkung zu OLG Düsseldorf, Beschluss vom 06.09.1983 - 5 Ss (OWi) 307/83-275/83 I. Juristische Rundschau, (6), 257-263.

Hurd, H. (2001). Is it wrong to do right when others do wrong?: a critique of American tort law. Legal Theory, 7(3), 307-340. doi: 10.1017/S1352325201073050

Jakobs, G. (1977). Regreßverbot beim erfolgsdelikt. Zugleich eine untersuchung zum grund der strafrechtlichen haftung für begehung. Zeitschrift für die gesamte strafrechtswissenschaft, 89(1), 1-35. doi: 10.1515/zstw.1977.89.1.1

Jakobs, G. (1993). Strafrecht, allgemeiner teil: die grundlagen und die zurechnungslehre. Berlin: De Gruyter. doi: 10.1515/9783110906424

Jakobs, G. (1996). Akzessorietät: Zu den voraussetzungen gemeinsamer organisation. Goltdammer's archiv für strafrecht, 1996, 253-268.

Jakobs, G. (2003). Beteiligung. En D. Dölling (Ed.), Jus humanum. Grundlagen des rechts und strafrecht festschrift fur Ernst-Joachim Lampe zum 70. Geburtstag (pp. 561-575). Berlin: Duncker \& Humblot. doi: 10.3790/978-3-428-51390-1

Jakobs, G. (2012). System der Strafrechtlichen zurechnung. Frankfurt am Main: Vittorio Klostermann.

Jakobs, G. (2014). Theorie der beteiligung. Tübingen: Mohr Siebeck.

Joecks, W. (2017). § 27 Beihilf. En B. Von Heintschel-Heinegg (Ed.), Münchener kommentar zum Strafgesetzbuch: §§ 1-37 (3a ed., Vol. 1, pp.1343-1376). München: C. H. Becks.

Kindhäuser, U. (1982). Kausalanalyse und Handlungszuschreibung, Goltdammer's Archiv für Strafrecht, 1982, 477-498.

Kindhäuser, U. (1989). Gefahrdung als straftat: rechtstheoretische untersuchungen zur dogmatik der abstrakten und konkreten gefahrdungsdelikte. Frankfurt am Main: V. Klostermann.

Kindhäuser, U. (1997). BGH, 18.04.1996 - 1 Str 14/96: Bestimmtheit des Gehilfenvorsatzes. Neue zeitschrift für strafrecht, 17(6), 272 -275.

Kindhäuser, U. (2007a). Zum Begriff der Beihilfe. En G. Dannecker, W, Langer, O. Ranft, R. Schimtz y J. Brammsen (Eds.), Festschrift für Harro Otto zum 70. Geburtstag am 01. April 2007(pp. 355-371). Köln: C. Heymanns.

Kindhäuser, U. (2007b). Der subjektive Tatbestand im Verbrechensaufbau. Zugleich eine Kritik der Lehre von der objektiven Zurechnung. Goltdammer's Archiv für Strafrecht, 154(8), 447-468. 
Kindhäuser, U. (2009). Die deutsche Strafrechtsdogmatik zwischen Anpassung und Selbstbehauptung - Grenzkontrolle der Kriminalpolitik durch die Dogmatik. Zeitschrift für die gesamte Strafrechtswissenschaft, 121(4), 954-964. doi: 10.1515/ZSTW.2009.954

Kindhäuser, U. (2010). Zum sog. „unerlaubten“ Risiko. En R. Bloy, M. Böse, T. Hillenkamp, C. Momsen y P. Rackhow (Eds.), Gerechte Strafe und legitimes Strafrecht Festschrift für Manfred Maiwald zum 75. Geburtstag (pp. 397-416), Berlín: Duncker \& Humblot. doi: 10.3790/978-3-428-52920-9

Kindhäuser, U. (2015a). Verursachen und Bedingungen. Zur Regressverbotslehre Reinhard Franks. En C. F. Stuckenberg y K. F. Gärditz (Eds.), Strafe und Prozess im freiheitlichen Rechtsstaat Festschrift für Hans-Ullrich Paeffgen zum 70. Geburtstag am 2. Juli 2015 (pp. 129-151). Berlín: Duncker \& Humblot. doi: 10.3790/978-3-428-54338-0

Kindhäuser, U. (2015b). Strafrecht Allgemeiner Teil (7a ed.). Baden-Baden: Nomos. doi: $10.5771 / 9783845263724$

Kindhäuser, U. (2018). Welzels Konzeption sozialer Adäquanz - normtheoretisch betrachtet. En B. Hecker, W. Weißer y C. Brand (Eds.), Festschrift für Rudolf Rengier zum 70. Geburtstag (pp. 49-58). Berlín: C.H. Beck.

Kudlich, H. (2002). "Neutrale Beihilfe” bei der Mitwirkung an der Sicherung der innerdeutschen Grenze - BGH. NJW 2001, 2409. Juristische Schulung, 42(8), 751-755.

Kudlich, H. (2004). Die Unterstützung fremder Straftaten durch berufsbedingtes Verhalten. Berlín: Duncker \& Humblot. doi: 10.3790/978-3-428-51444-1

Kudlich, H. (2008). Tiroler Gastfreundschaft auch für deutsches Geld - Anstiftung zur Steuerhinterziehung durch berufsbedingtes Verhalten?. En U. Sieber, G. Dannecker, U. Kindhäuser, J. Vogel y T. Walter (Eds.), Strafrecht und Wirtschaftsstrafrecht: Dogmatik, Rechtsvergleich, Rechtstatsachen ; Festschrift für Klaus Tiedemann zum 70. Geburtstag (pp. 221-236). Köln: Heymann.

Lesch, H. (2014). Beihilfe durch „rollenadäquates“ Verhalten?. En K. Lüderssen, K. Volk, y E. Wahle (Eds.), Festschrift für Wolf Schiller zum 65. Geburtstag am 12. Januar 2014 (pp. 448-473). Baden-Baden: Nomos. doi: 10.5771/9783845244099

López Díaz, C. (Trad.). (1999). Código penal alemán (STGB): del 15 de mayo de 1871, con la última reforma del 31 de enero de 1998. Bogotá: Universidad Externado de Colombia. Recuperado de https://bit.ly/3t0ymnZ

Löwe-Krahl, O. (1995). Beteiligung von Bankangestellten an Steuerhinterziehungen ihrer Kunden -die Tatbestandsmäßigkeit berufstypischer Handlungen. Wistra (Heidelberg), (6), 201-206. 
Mañalich Raffo, J. P. (2015). Erlaubnisnormen und Duldungspflichten. Rechtsphilosophie (München. Beck), 1(3), 288-323. doi: 10.5771/2364-1355-2015-3-288

Meyer-Arndt, L. (1989), Beihilfe durch neutrale Handlungen?. Wistra (Heidelberg), (8), 281-287.

Momsen, C. (2010). Neutralen Verhaltensweisen und Unterlassungen im Insiderstrafrecht. En R. Bloy, M. Böse. T. Hillenkamp, C. Momsen, y P. Rackow (Eds.), Gerechte Strafe und legitimes Strafrecht Festschrift für Manfred Maiwald zum 75 (pp. 561-584). Geburtstag. Berlin: Duncker \& Humblot. doi: 10.3790/978-3-428-52920-9

Naucke, W. (1964). Über das Regreßverbot im Strafrecht. Zeitschrift für die gesamte Strafrechtswissenschaft, 76(3), 409-440. doi: 10.1515/zstw.1964.76.3.409

Niedermaier, H. (1995). Straflose Beihilfe durch neutrale Handlungen?. Zeitschrift für die gesamte Strafrechtswissenschaft, 107(3), 507-544. doi: 10.1515/zstw.1995.107.3.507

Otto, H. (1998). ",Vorgeleistete Strafvereitelung” durch berufstypische oder alltägliche Verhaltensweisen als Beihilfe". En A. Eser, U. Schittenhelm, y H. Schumann (Eds.), Festschrift für Theodor Lenckner : zum 70. Geburtstag. Múnich: C. H. Beck, pp. 193-225.

Otto, H. (2001). Das Strafbarkeitsrisiko berufstypischen, geschäftsmäßigen Verhaltens. JuristenZeitung, 56(9), 436-444. Recuperado de https://bit.ly/3eCjQ0x

Otto, H. (2004). Grundkurs Strafrecht. Allgemeine Strafrechtslehre (7a ed.). Berlín: De Gruyter. doi: 10.1515/9783110915686

Otto, H. (2008). Buchbesprechung. Zeitschrift für die gesamte Strafrechtswissenschaft, 120(2), 418-425. doi: 10.1515/ZSTW.2008.418

Philipowski, R. (1983). Steuerstrafrechtliche Probleme bei Bankgeschäften. En G. Kohlmann, (Ed.), Strafverfolgung und Strafverteidigung im Steuerstrafrecht: Grundfragen des Steuerstrafrechts heute (pp. 131-153). Köln: Otto Schmidt.

Puppe, I. (1998). Die Lehre von der objektiven Zurechnung dargestellt an Beispielsfällen aus der höchstrichterlichen Rechtsprechung; IV. Zurechnung bei mehreren Beteiligten. Juristische Ausbildung, 1998, 21-31.

Puppe, I. (2017). Vorbemerkungen zu §§ 13 ff. En U. Kindhäuser, U. Neumann, y H. U. Paeffgen (Eds.), Strafgesetzbuch (5a ed., Vol. 1, NomosKommentar, pp. 513-649). Baden-Baden: Nomos.

Rackow, P. (2007). Neutrale Handlungen als Problem des Strafrechts. Frankfurt am Main: Peter Lang.

Ransiek, A. (1997). Pflichtwidrigkeit und Beihilfeunrecht. Wistra (Heidelberg), 16(2), 41 47. 
El tratamiento de las denominadas acciones neutrales a título de complicidad...

Rengier, R. (2016). Strafrecht Allgemeiner Teil (8a ed). München: C. H. Beck.

Robles Planas, R. (2003). La participación en el delito: fundamentos y límites. Madrid: Marcial Pons.

Roca de Agapito, L. (2008). Límites de la responsabilidad penal por actividad (profesional) cotidiana. Estudios penales y criminológicos, (28), 343-395. Recuperado de https://bit.ly/3u40GHo

Roxin, C. (1983). Bemerkungen zur sozialen Adäquanz im Strafrecht. En G. Kohlmann (Ed.), Festschrift für Ulrich Klug zum 70. Geburtstag (Vol. 2, pp. 303-313). Köln: Dr. Peter Deubner.

Roxin, C. (1989). Bemerkungen zum Regreßverbot. En H.-H. Jescheck y T. Vogler (Eds.), Festschrift für Herbert Tröndle zum 70. Geburtstag am 24. August 1989 (pp. 177200). Berlin: De Gruyter. doi: 10.1515/9783110892079-011

Roxin, C. (1993a). Zum Strafgrund der Teilnahme. En F. Dencker, W. Küper, y J. Welp (Eds.), Beiträge zur Rechtswissenschaft: Festschrift für Walter Stree und Johannes Wessels zum 70. Geburtstag (pp. 365-382). Karlsruhe: C. F. Müller.

Roxin, C. (1993b). Strafgesetzbuch: Leipziger Kommentar: §§ 25-27 (11a ed., Vol. 8, Großkommentare der Praxis) (B. Jähnke, H. W. Laufhütte, \& W. Odersky, Eds.). Berlin: W. de Gruyter.

Roxin, C. (1995) "Was ist Beihilfe?". En H. H. Kühne (Ed.), Festschrift für Koichi Miyazawa: dem Wegbereiter des japanisch-deutschen Strafrechtsdiskurses (pp. 501-517). BadenBaden: Nomos.

Roxin, C. (2003). Strafrecht Allgemeiner Teil: Besondere Erscheinungsformen der Straftat (4a ed., Vol. 2). München: C. H. Beck.

Roxin, C. (2006). Strafrecht Allgemeiner Teil: Grundlagen der Aufbau der Verbrechenslehre (4a ed., Vol. 1). München: C. H. Beck.

Roxin, C. (2006b). Derecho penal, parte general: fundamentos. La estructura de la teoría del delito (Vol. 1) (D. M. Luzón Peña, M. Díaz y García Conlledo, y J. De Vicente Remesal, Trads.). Madrid: Civitas.

Rueda Martín, M. Á. (2015). De nuevo sobre la relevancia penal de las acciones cotidianas en la comisión de un hecho doloso. Cuadernos de política criminal, (115), 3586. Recuperado de https://bit.ly/3e360VP

Schall, H. (2002). Strafloses Alltagsverhalten und strafbares Beihilfeunrecht. En E. Graul y G. Wolf, (Eds.), Gedächtnisschrift für Dieter Meurer (pp. 103-122). Berlin: De Gruyter. doi: 10.1515/9783110891522.103 
Schild, W. (2017). § 27 Beihilfe. En U. Kindhäuser, U. Neumann, y H. U. Paeffgen (Eds.), Strafgesetzbuch (5a ed., Vol. 1, NomosKommentar, pp. 1269-1278). Baden-Baden: Nomos.

Schumann, H. (1986). Strafrechtliches Handlungsunrecht und das Prinzip der Selbstverantwortung der Anderen. Tübingen: J.C.B. Mohr.

Schünemann, B. (2007). § 27 Beihilfe. En H. W. Laufhütte, R. Rissing-van Saan, y K. Tiedemann, Leipziger Kommentar zum Strafgesetzbuch (12a ed., Vol. 1, pp. 2027-2063). Berlin: De Gruyter.

Schünemann, B. (2012). Standpunkte der deutschen Strafrechtslehrer zu den Zukunftsperspektiven der Rechtswissenschaft und der akademischen juristischen Ausbildung in Deutschland. Zeitschrift für internationale Strafrechtsdogmatik, (6), 302-311. Recuperado de https://bit.ly/3el17Rs

Schurmann Opazo, M. (2019). ¿Es científico el discurso elaborado por la dogmática jurídica?: una defensa de la pretensión de racionalidad del discurso dogmático elaborado por la ciencia del derecho penal. Política criminal, 14(27), 549-598. doi: $10.4067 /$ S0718-33992019000100549

Schurmann Opazo, M. (2020). Una aproximación crítica a la denominación de acciones de colaboración como neutrales. Revista chilena de derecho, 47(1), 261-283. doi: $10.4067 /$ S0718-34372020000100261

Searle, J. R. (1997). La construcción de la realidad social (A. Domènech, Trad.). Barcelona: Paidós.

Seher, G. (2009). Grundfälle zur Beihilfe. JuS, (9), 793-797.

Silva Sánchez, J. M. (2008), Zur Beteiligung von Notaren an Vermögens und Wirtschaftsstraftaten. En U. Sieber, G. Dannecker, U. Kindhäuser,J. Vogel, y T. Walter (Eds), Strafrecht und Wirtschaftsstrafrecht: Dogmatik, Rechtsvergleich, Rechtstatsachen; Festschrift für Klaus Tiedemann zum 70. Geburtstag (pp. 237-252). Köln: Carl Heymanns.

Steuerhinterziehung u. a., 5 StR 746/97 (Bundesgerichtshof 26. Oktober 1998). Recuperado de https://bit.ly/2SBNb3L

Strafgesetzbuch. 15. Mai 1871. Recuperado de https://bit.ly/31WbWZW

Strafsache gegen wegen Beihilfe zum versuchten Betrug, 5 StR 468/12 (Bundesgerichtshof 22. Januar 2014). Recuperado de https://bit.ly/3fjhmV5

Tisnado Solís, L. (2018). Fundamentos normativos de la intervención delictiva y responsabilidad penal. Santiago: Hammurabi. 
El tratamiento de las denominadas acciones neutrales a título de complicidad...

Viveros Vergara, M. (2013). Sobre los límites de la complicidad. En A. van Weezel de la Cruz (Coord.), Humanizar y renovar el derecho penal: estudios en memoria de Enrique Cury (pp. 659-675). Santiago: Thomson Reuters.

Vogel, J. (1993). Norm und Pflicht bei den unechten Unterlassungsdelikten. Berlin: Duncker \& Humblot. doi: 10.3790/978-3-428-47822-4

Waffengesetz. Bundesgesetzblatt I, República Federal Alemana, 11 de octubre de 2002. Recuperado de https://bit.ly/3h23uBc

van Weezel de la Cruz, A. (2007). Delitos tributarios. Santiago: Jurídica de Chile.

Welzel, H. (1975). Abhandlungen zum Strafrecht und zur Rechtsphilosophie, Berlin: De Gruyter. doi: 10.1515/9783110892666

Wiegand, T. (1998) "Grenzen strafbarer Beihilfe". En A. Eser, (Ed.), Festschrift für Haruo Nishihara zum 70. Geburtstag (pp. 197-212). Baden-Baden: Nomos.

Wohlers, W. (2000). Hilfeleistung und erlaubtes Risiko - zur Einschränkung der Strafbarkeit gemäß § 27 StGB". Neue Zeitschrift für Strafrecht, (4), 169-174.

Wohlleben, M. (1996). Beihilfe durch äußerlich neutrale Handlungen. München: C.H. Beck.

von Wright, G. H. (1963). Norm and Action: a logical enquiry. London: Routledge \& Kegan Paul. Recuperado de https://bit.ly/3e8cUcC

von Wright, G. H. (1974). Normenlogik. En H. Lenk, (Ed.), Normenlogik: Grundprobleme der deontischen Logik (pp. 25-38). Pullach: Verlag Dokumentation.

X. gegen Schweizerische Pay-Sat AG, BGE 114 IV 112 (Schweizerisches Bundesgericht 13. Juni 1988). Recuperado de https://bit.ly/2Sqh9b4

\section{Para citar este artículo bajo Norma APA 6a ed.}

Schurmann Opazo, M. A. (2021). El tratamiento de las denominadas acciones neutrales a título de complicidad en el derecho penal alemán. Revista de derecho (Coquimbo. En línea), 28, e3651. https://doi.org/10.22199/issn.0718-9753-2021-00012

Copyright del articulo: @2021 Miguel Schurmann

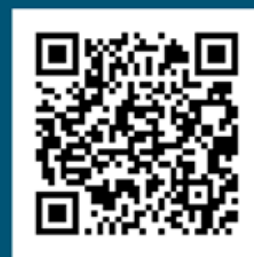

DOI

(cc) BY

Este es un artículo de acceso abierto, bajo licencia Creative Commons BY 4.0. 